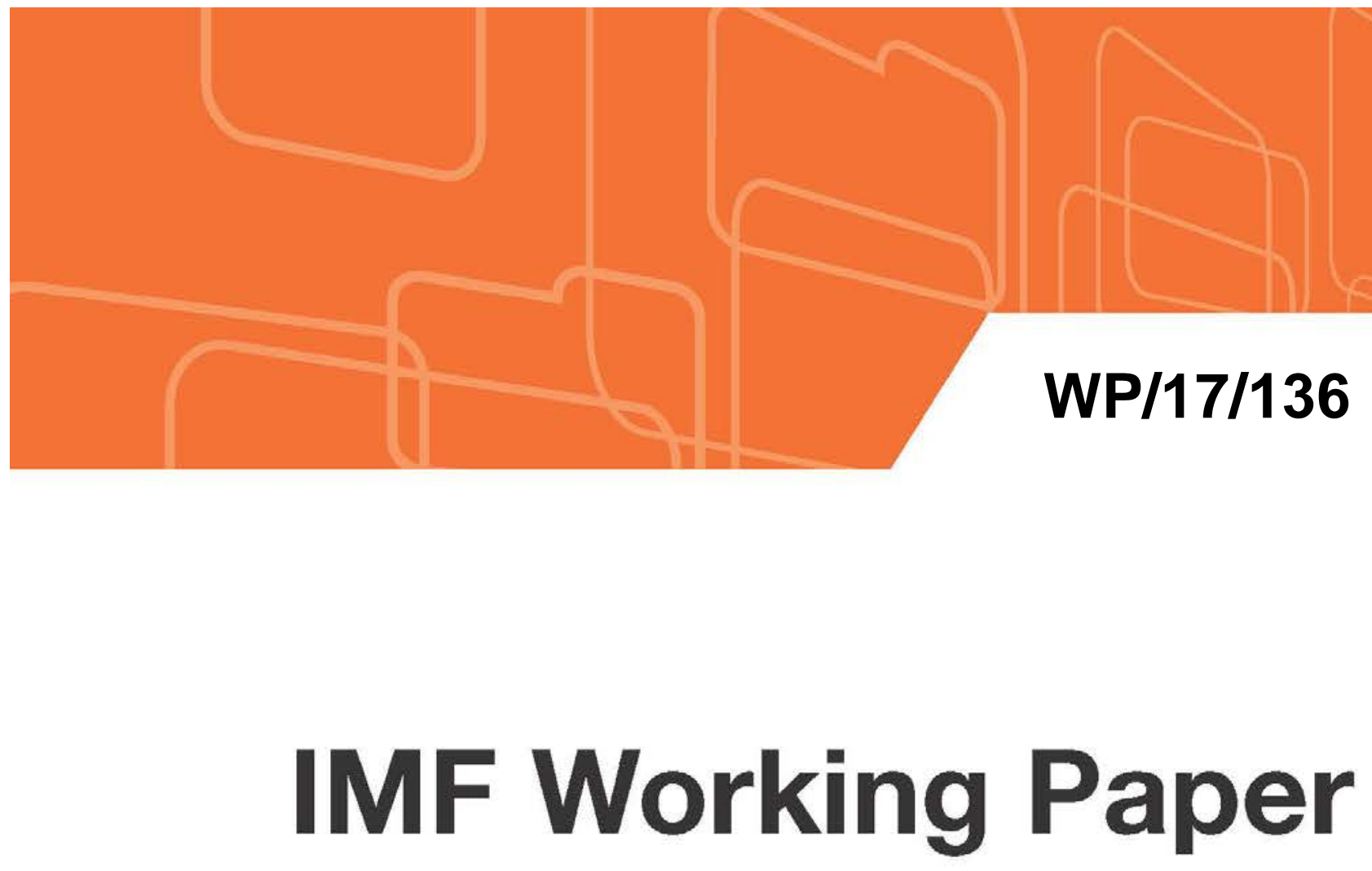

\title{
ABBA: An Agent-Based Model of the Banking System
}

\author{
by Jorge A. Chan-Lau
}

IMF Working Papers describe research in progress by the author(s) and are published to elicit comments and to encourage debate. The views expressed in IMF Working Papers are those of the author(s) and do not necessarily represent the views of the IMF, its Executive Board, or IMF management. 


\title{
IMF Working Paper
}

Institute for Capacity and Development

\author{
ABBA: An Agent-Based Model of the Banking System \\ Prepared by Jorge A. Chan-Lau \\ Authorized for distribution by Ralph Chami
}

June 2017

\begin{abstract}
IMF Working Papers describe research in progress by the author(s) and are published to elicit comments and to encourage debate. The views expressed in IMF Working Papers are those of the author(s) and do not necessarily represent the views of the IMF, its Executive Board, or IMF management.
\end{abstract}

\begin{abstract}
A thorough analysis of risks in the banking system requires incorporating banks' inherent heterogeneity and adaptive behavior in response to shocks and changes in business conditions and the regulatory environment. ABBA is an agent-based model for analyzing risks in the banking system in which banks' business decisions drive the endogenous formation of interbank networks. ABBA allows for a rich menu of banks' decisions, contingent on banks' balance sheet and capital position, including dividend payment rules, credit expansion, and dynamic balance sheet adjustment via risk-weight optimization. The platform serves to illustrate the effect of changes on regulatory requirements on solvency, liquidity, and interconnectedness risk. It could also constitute a basic building block for further development of large, bottom-up agent-based macro-financial models.
\end{abstract}

JEL Classification Numbers: G21, G28, G32

Keywords: agent-based model, banks, regulation, financial stability, solvency, liquidity, interconnectedness, NetLogo

Author’s E-Mail Address: jchanlau@imf.org 


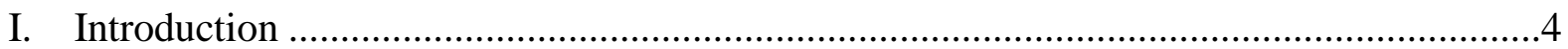

II. Related Literature .....................................................................................................6

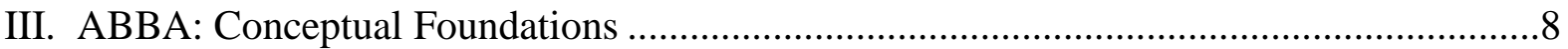

IV. Banks’ Behavioral Decisions and Interactions with Other Agents ....................................12

V. A Simulation Exercise: Capital and Liquidity Requirements, Interconnectedness, and

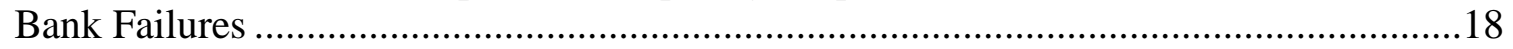

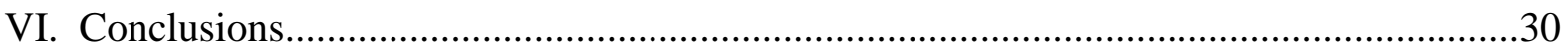

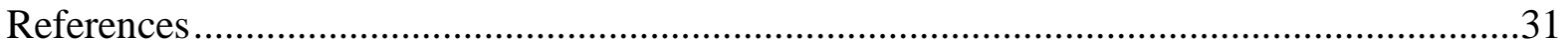

\section{Figures}

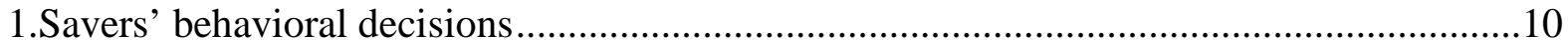

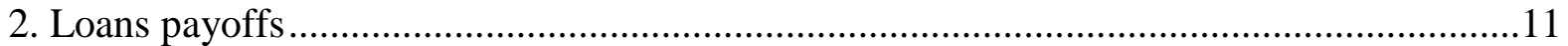

3. Bank's actions and interactions with other agents ..............................................................13

4. Average reserve ratio for different regulatory requirements ...............................................21

5. Mean capital ratio for different regulatory requirements.....................................................2

6. Mean return on equity under different regulatory requirements, in percent ........................24

7. NetLogo implementation of ABBA showing interbank loans.........................................25

8. In-degree and Out-degree dynamics for a representative bank ...........................................22

9. Percent of times out-degree of a bank exceeds one ...........................................................27

\section{Tables}

1. Credit and liquidity failures for different regulatory requirements, in percent....................22

2. Banks' in-degree for different regulatory requirements, in percent ....................................28

3. Banks' out-degree for different regulatory requirements, in percent ..................................29 


\section{INTRODUCTION ${ }^{1}$}

The banking system, which lies at the core of the financial system, suffered during the financial crisis in 2007-9. In the United States alone, in the four years following the inception of the crisis in 2008, the number of failed banks in the United States reached 414 . The costs associated to the crisis have been enormous. Estimates by Atkinson, Luttrell, and Rosenblum (2013) place the costs in the range of 100 to 190 percent of 2007 GDP, if measured in terms of lost income implied by the path of consumption. Extraordinary government support to manage the crisis amounted to around 85 percent of 2007 GDP.

As a response to the crisis, research work has focused towards understanding and measuring vulnerabilities in financial systems, and especially, on financial networks. On the latter, the analysis centers on evaluating the topological properties of static networks representing the state of nature at a given point in time. Systemic risk, and vulnerabilities, can be associated to a number of centrality measures, such as the number of connections of one institution with others in the network (or degree). ${ }^{2}$

Understanding what the main drivers of temporal changes in the network topology are, however, has received less attention. Linkages, or connections, between different participants in the financial system arise from voluntary contractual arrangements, and from business strategies exposing them to common sources of shocks. Moreover, the decisions of the financial agents should account for the requirements imposed by the regulatory regime, as well as the decisions of other agents.

The adaptive behavior of financial agents, therefore, determines the aggregate characteristics of the financial system, including its interconnectedness. In other words, the rules governing the behavior of microscopic agents underlie observed aggregate, macroscopic behavior. Microscopic behavior does not necessarily need to resemble macroscopic behavior. For instance, Gode and Sunder (1993) show that non-rational behavior of zero-intelligence traders yields allocation outcomes close to those predicted by neo-classical economics.

Modeling adaptive behavior requires allowing for heterogeneity in the system, as initial conditions affect the behavior of an individual agent, and for sub-optimal behavior, since it is

\footnotetext{
1 The author benefitted from comments by Simin Cao, Lilly Chan, Andrew Crooks, Dimitri Demekas, Ou Jing, William Kennedy, Weimin Miao, Wenting Peng, Sun Yu, Haoyu Zheng, Yongying Zhong, and seminar participants at George Mason University, Department of Computational Social Science; and the Monetary Authority of Singapore. Some of the work reported here was conducted while the author was on sabbatical leave as a Senior Research Fellow at the Risk Management Institute, the National University of Singapore. Any errors or omissions are the sole responsibility of the author.

2 See Allen and Babus (2009), Cont et al (2013) and Upper (2011) among others; and IMF (2013) for a policy application. For textbook treatments, see Chan-Lau (2013) and Gai (2013). More general treatments of economic and financial networks are presented in Jackson (2010) and Easley and Kleinberg (2010). The recent launch of the Journal of Network Theory in Finance highlights the increased attention devoted to financial networks.
} 
often the case that rules of thumb rather than solutions to profit and/or utility maximization problems guide strategic decisions.

Accommodating heterogeneity and rules of thumb is not a particular strength of the standard analytical tools typically used by macroeconomists, central banks, and regulatory agencies. In most cases, the workhorse model is a dynamic stochastic general equilibrium model, whose formulation and numerical solution depends on strong, simplifying assumptions (MAG, 2010; Rogers and Vlcek, 2012). At the risk of oversimplification, in a majority of these models the macroscopic equilibrium solution follows from the decisions of an aggregate representative agent in the economy, which behaves similarly to the microscopic agents. Hence, these models rule out the emergence of aggregate behavior.

Rather than attempting to model the behavior of individual agents, an alternative approach is to estimate econometric and statistical techniques to infer linkages and shock spillovers across financial institutions. Reliance on past data, however, reduces the ability of these models to capture the effects of regime changes. An econometric model, estimated using data predating the introduction of the Basel III regulatory reforms, may provide poor guidance on the likely impact of the reforms going forward.

In contrast, agent-based models (ABMs) are specially suited to deal with large degree of heterogeneity, including diverse rules of behavior spanning both optimal and suboptimal strategies. As argued strongly by Bookstaber (2012), ABM models serve as useful platforms for analyzing risks in financial systems, and computational laboratories for evaluating what-if scenarios generated by competing policy proposals. ${ }^{3}$

This paper introduces an agent-based model for banking analysis, ABBA. The model builds a relatively simple but richly detailed banking system to understand the dynamics of solvency, liquidity and interconnectedness risk in response to shocks. The model includes three types of agents: savers, loans (or borrowers), and banks, expanding on the number of agents in earlier models such as Montagna and Koc (2013). Similar to earlier ABMs of the banking system, interbank loans are the only source of interconnectedness in the system. The interbank network structure is not exogenous, as in the models of Georg (2013) and Lenzu and Tedeshi (2012), but arises endogenously as banks access it to meet their liquidity needs, as in Anselmo and Planck (2012) and Klinger and Teply (2014).

Compared to earlier ABM models, ABBA allows banks to have a rich set of behavioral decision, perhaps being C.R.I.S.I.S. the only exception. First, ABBA models dividend payments explicitly, imposing a dividend rule policy. The policy allows payments only if the bank meets its own internal capital and reserve requirements. Second, banks in ABBA can continue expanding their loan portfolios in order to better utilize their excess reserves. Finally, banks can rebalance their loan portfolios, i.e. perform risk-weight optimization, whenever they fail to meet capital requirements. This reflects the capital management strategies banks follow in the real world (Babel et al, 2012).

\footnotetext{
${ }^{3}$ See Gaffard and Napoletano (2012) for broader applications to economic policy.
} 
This last feature of ABBA stands in sharp contrast with models that force the failure of the bank once the capital ratios drop below minimum regulatory requirements. In ABBA, managers can take remedial actions to improve its capital position, albeit at the cost of deleveraging or shrinking its balance sheet. By allowing develeraging, ABBA can serve to analyze how stricter capital requirements reduce the overall credit supply in the economy.

The holistic approach embedded in the ABM formulation permits analyzing the risks in the banking system conditional on the regulatory environment. The paper illustrates this by revising briefly the links between regulatory requirements and solvency, liquidity, and interconnectedness risk using numerical simulations. When capital requirements are too low relative to the underlying credit risk in the banks' loan portfolios, raising reserve requirements could lead to larger number of bank failures. Higher capital requirements, by reducing counterparty risk, are conducive to higher interconnectedness risk. In tranquil periods, this may not pose problems but it could constitute a potential systemic vulnerability in the event that tail risk leads to the failure of one bank. A companion paper, Chan-Lau (2014), describes the numerical experiments in more detail.

Notice that the modular approach of ABBA facilitates its extension and customization. ABBA currently describes a traditional banking system funded by deposits, a situation reflecting the reality in many countries. Introducing wholesale funding, systemic default risk in the non-bank financial sector, and more complex sources of interbank exposures, such as collateralized lending is straightforward. It involves modifying some of the attributes of existing agents and adding new agents to the system.

The organization of the remainder of the paper is the following. Section II reviews the related literature ahead of the conceptual presentation of the ABBA model in Section III. Section IV describes in detail the equations ruling the behavioral decisions in ABBA, and Section $\mathrm{V}$ illustrates the use of the ABBA framework to analyze the interplay between regulatory requirements and risks in the banking system. Finally, section VI concludes discussing possible extensions to the framework.

\section{RELATED LiterATURE}

Unsurprisingly, the number of studies analyzing banking and financial systems using ABMs has increased rapidly in recent years, so this review of the literature is by no means comprehensive, and cannot do justice to past and ongoing work in this area.

Anselmo and Planck (2012) examine bank solvency in a stylized model of the banking system. There are three different types of banks differentiated by their risk profiles - least risky banks, middle-risk banks, and risky banks - as well as a lender of last resort. Banks can invest in safe household loans or in a risky investment in the non-bank sector, and interbank connections arise when banks borrow from others to meet short-term reserve and solvency requirements. Interbank loans are payable either in one day or three days. The authors find that the length of the payback period affects the number of connections in the system. A one- 
day payback period leads to a less connected system, increasing the centrality (or systemic importance) of individual banks.

Risk management practices, such as Value-at-Risk, place constraints on banks encouraging them to increase their leverage during periods of low risk, and reduce it rapidly as risk increases. Aymanns and Farmer (2015) argue that the leverage cycle emerges endogenously in a system where banks rely only on historical data to estimate the risks in their portfolios. The boundedly rational behavior imposed by data constraints lead banks to overshoot or undershoot their leverage targets. As in Anselmo and Plack (2012), banks use a heuristic portfolio selection rule rather than portfolio optimization. In this framework, countercyclical policy allowing leverage to increase during high volatility episodes could help reduce the amplitude of the leverage cycle. Fixed leverage limits, regardless of the level of market volatility, could also dampen the leverage cycle provided they are set at low levels.

Grilli, Tedeschi, and Gallegati (2015) introduce a model populated by heterogeneous firms that obtained loans from multiple banks. Interbank linkages arise when banks facing loan demands exceeding their resources borrow from other banks with surpluses. The fragility of the banking system is proportional to the number of interbank linkages. Shocks arising in the real sector, e.g. firms, affect the lending bank, and potentially, the rest of the banking system through interbank exposures.

Most studies take for granted the existence of a banking system. This is not the case in Ismail (2012), where the banking system emerges naturally to meet the liquidity needs of a population of heterogeneous individuals. Similarly to Diamond and Dybvig (1983), but without recurring to a priori equilibrium assumptions, Ismail's model not only explains the emergence of a banking system but the possibility of bank runs. Extensions of the model, allowing for banks learning from their past experience, allow for the endogenous formation of interbank linkages.

Relationships can contribute to the formation of interbank networks, as shown in Lenzu and Tedeshi (2012). Banks follow preferential attachment rules, equivalent to contingent lending agreements, to decide whether they will provide funding to other banks experiencing liquidity shortages. The probability that a bank may receive funding is proportional to its profit levels. Hence, high profitable banks have stronger "relationships" with their peers than less profitable banks. The interbank network topological characteristics depend on the level of profitability required by the preferential attachment rule, with different levels giving rise to structures ranging from random graphs to power-law networks.

Georg (2013) introduces a system where banks differ in their risk, return, and liquidity preferences. Interbank loans, necessary to meet liquidity shortages, link banks with each other. The system also includes a central bank, which can provide liquidity against collateral. Georg tests the resilience of different interbank network structure to liquidity shocks affecting the supply of deposits. Contrary to other work cited here, the interbank network structure is exogenous to the system. During tranquil periods, the network structure is irrelevant to the stability of the system. During distress periods, however, networks characterized by money centers, i.e. banks with a high degree of centrality compared to other 
banks, exhibit more stability than purely random networks. Central banks, by providing liquidity, can reduce the degree of instability in the system albeit only in the short-run. In the long-run, banks with liquidity positions supported by central bank assistance reestablish linkages with healthier banks, making the system more interconnected and fragile.

Stress tests, which assess banks' resilience to negative macroeconomic shocks, have become important tools for managing risks in banks (Scheule and Roesch, 2008) and guiding bank supervision and regulatory policy (IMF, 2012; Siddique and Hasan, 2013; and Zhang, 2014). Klinger and Teply (2014) describe how an ABM is useful for conducting stress tests of the banking system. The interbank network is a random network, where there is an identical and independent probability of interbank exposures between any pair of banks. The interbank network strucrture, as in Georg (2013), is exogenous and it is not the result of the adaptive behavior of banks. Shocks to the asset side of the balance sheet of banks propagate through the interbank network, and can potentially trigger a cascade of failures. Capital requirements can help protect the system by reducing the likelihood of a cascade of failures, but once it has started, capital requirements may have the perverse effect of accelerating the pace of failures.

Montagna and Koc (2013) analyze interbank exposures through three different channels: short-term interbank loans, long-term interbank loans, and exposures to common assets. On a bigger scale, the Complexity Research Initiative for Systemic Instabilities (C.R.I.S.I.S) has

developed a large macro-financial ABM for the European economy. Axtell et al (2014), using data on real estate transactions, have modeled the housing market in D.C. including households and banks as agents.

Although most of the models reviewed above focus on the banking system, ABMs are useful for analyzing other sectors of the financial system. Bookstaber, Paddrik, and Tivnan (2014) capture how fire sales, prompted by credit shocks and funding shocks, propagate in a financial system composed of fund suppliers, financial institutions trading in the asset market, and the bank/dealers that intermediate between them. Since the model can capture the second-round effects triggered by the initial losses following a shock, the authors argue it could serve for extending risk management beyond standard VaR measures.

Motivated by the observation that liquidity in financial markets dries up during crisis periods, Bookstaber and Paddrik (2015) examine the interaction between agents demanding liquidity, agents supplying it, and market makers in the presence of exogenous liquidity shocks in a limit-order book framework. The policy implications of their work suggest that circuit breakers, exceptional funding to broker-dealers and the role of the government as a liquidity supplier of last resort could reduce the disruptions caused by liquidity shocks.

\section{ABBA: CONCEPTUAL FOUNDATIONS}

The construction of ABBA follows a modular approach to allow future extensions, including the addition of new agents and/or the specification of new behavioral rules governing agents' responses. ABBA is implemented in NetlLogo, a specialized multi-agent modeling environment (Wilensky, 1999). 
The model considers three types of agents in the banking system: savers, loans, and banks, and one type of interbank linkages, interbank loans. I choose loans as agents rather than the corresponding debtor firm. While this choice appears counterintuitive, the loan characteristics rather than the corporations per se are the relevant factors for analyzing credit risk in the bank loan portfolio. This is not a far-fetched assumption. In real life, a single corporation may issue several obligations with different ratings and under different covenants. Therefore, the credit risk of each obligation is different regardless of having a common issuer.

Not all the agents in the model are "agents" according to the criteria proposed by North and Macal (2005). In their view, agents should exhibit four characteristics: adaptive behavior; or the capability to respond to other agents and its environment; capability to learn and modify their behavior; autonomy; and heterogeneity.

In ABBA, banks exhibit all four characteristics and qualify as agents. Savers are heterogeneous and exhibit some simple adaptive behavior, but do not modify it nor exhibit autonomy. Loans and interbank loans lack all characteristics except heterogeneity. Savers, loans, and interbank loans are what North and Macal denominate proto-agents. For simplicity purposes, we refer here to both proto-agents and agents as agents.

The agents inhabit a world divided in different regions. In this world, both the savers and loans are homogenously distributed across regions. In the initial stage, each region is dominated by a regional bank, which raises deposits from savers and makes loans to corporations. In subsequent stages, banks may start raising deposits and extending loans in different regions. This assumption is not crucial for analyzing risks in the banking system, but sets the required background for understanding the dynamics of cross-border banking.

\section{A. Savers}

Savers are homogeneously distributed in different regions of the world, each of which is dominated by one bank. Savers with outstanding balances at solvent banks receive interests on their deposits. The interest payments are consumed and not reinvested in the bank account, leaving the balance unchanged from one period to the other. Figure 1 summarizes the behavioral decisions of the saver. 
Figure 1. Savers' behavioral decisions

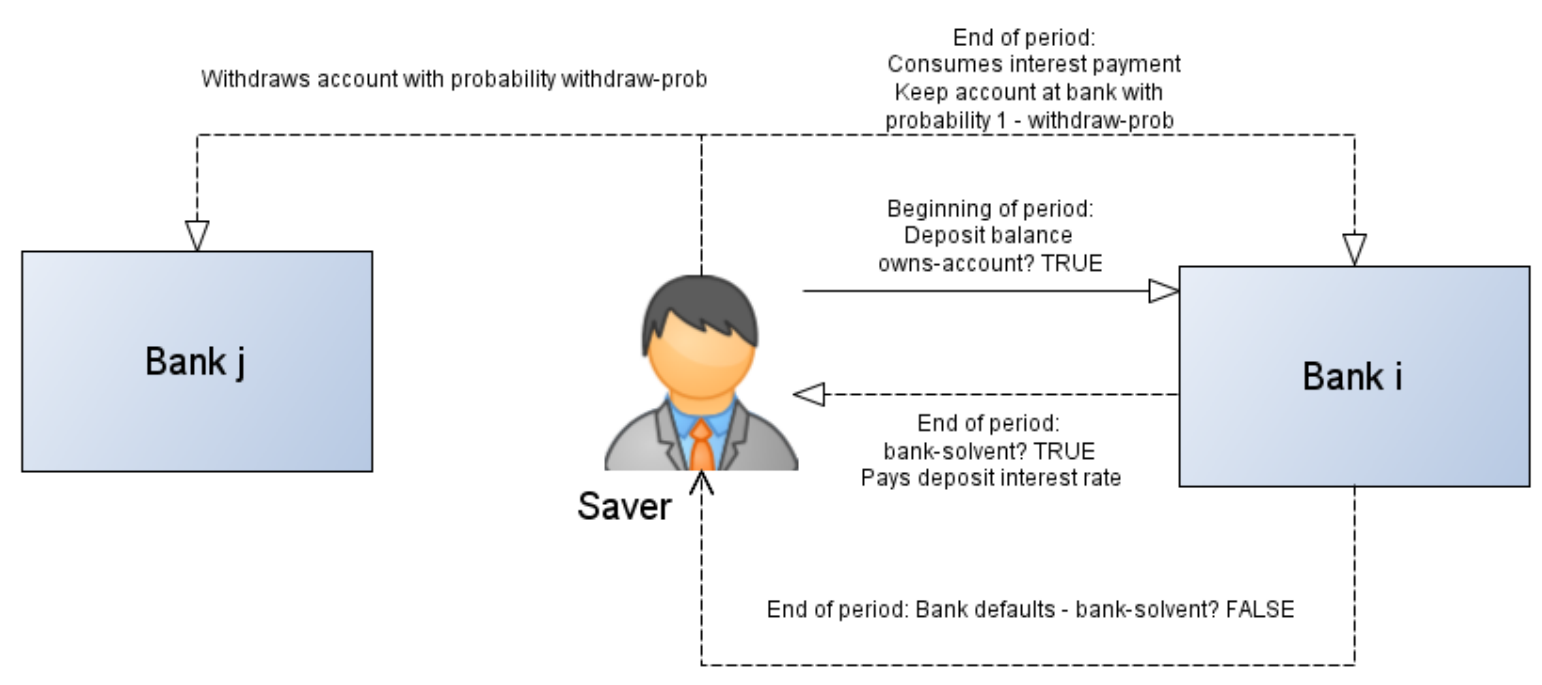

Saver recovers deposits if value of liquidated portfolio and reserves exceeds bank deposits

Otherwise, first-come, first-serve applies

After interests and principal are paid, savers may withdraw their deposits from the bank with an exogenous probability, relocate to other region and open an account with the corresponding regional bank. If the saver owns an account with a bank that deleverages to optimize its risk-adjusted capital ratio, it may be possible that the saver's account is closed with the balance of the account returned in full to the saver (see below).

There is no deposit insurance in this model. Savers who own an account remain solvent as long as the bank does not default. In the case of a bank default, its loan portfolio is liquidated at a loss owing to haircuts, reflecting either fire-sale losses or less-than-face value recovery rates for liquidated loans. The proceeds from the liquidated loan portfolio and the available reserves are used to return savers' balances. In case that the proceeds are not sufficient to compensate all savers, they get paid on a first-come, first-serve basis. Savers that arrive late are not paid and become insolvent.

\section{B. Loans}

As is the case with savers, loans are distributed homogenously in different regions. Each loan has a number of intrinsic attributes, including the loan amount, probability of default, risk weight, rating, recovery rate in case of default, and loss rates associated with fire sales.

Based on the credit risk characteristics of the loan (probability of default and recovery rate given default), the bank quotes a loan rate to the borrower at the beginning of the period following a simple pricing rule. When a firm approaches the bank for a loan, the bank produces the rate quote as long as the bank remains compliant with capital and reserve requirements after adding the loan to the current loan portfolio (Figure 2). 
Figure 2. Loans payoffs

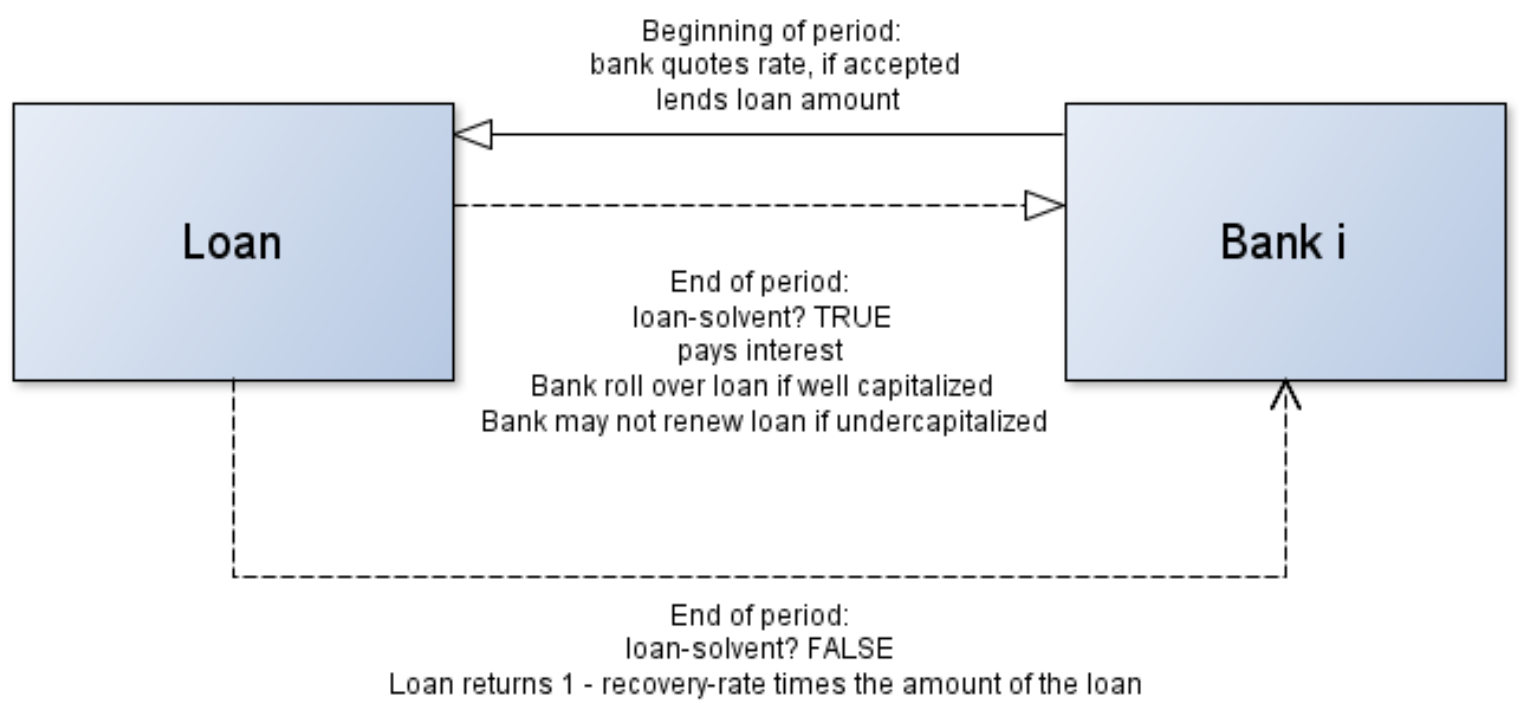

From the perspective of the bank, there is a trade-off between the high returns offered by the loan and its associated costs, which work against meeting regulatory requirements. They include the need to increase provisions against expected losses, which is done by depleting earnings which otherwise will accrue to equity capital; an increase in risk-weighted assets, and the shift of reserves to illiquid loans.

The borrower accepts the loan rate quote if it is lower than its reservation interest rate, a variable not observed by the bank. In this case, the loan is approved by the bank. A loan that remains current at the end of the period returns the agreed loan interest rate to the bank, and in turn, the bank rolls over the loan. If the loan defaults, the bank obtains the recovery amount equal to the recovery rate times the amount of the loan.

\section{Banks}

Banks are the most complex agents in ABBA. Banks need to raise deposits, deploy these deposits to fund risky loans while at the same time provisioning against expected losses. Banks also need to determine the amount of equity and reserves needed to satisfy minimum regulatory capital and reserve requirements. Solvent banks not meeting the requirements could deleverage or conduct risk-weight optimization to increase its reserves and boost is capital to risk weighted assets. Unsecured interbank loans from banks with excess reserves could serve to meet the reserve requirement. Figure 3 illustrates the different decisions a bank must take and its interaction with the other agents in the system. The next section offers a formal description of these rules. 
Figure 3. Bank's actions and interactions with other agents

The solid red line represents the loop induced by second-round effects; the solid blue line the loop induced by risk-weight optimization actions by the bank; and the dashed red lines the flows and decisions following the completion of the second-round effect and risk-weight optimization loops (see section III for details).

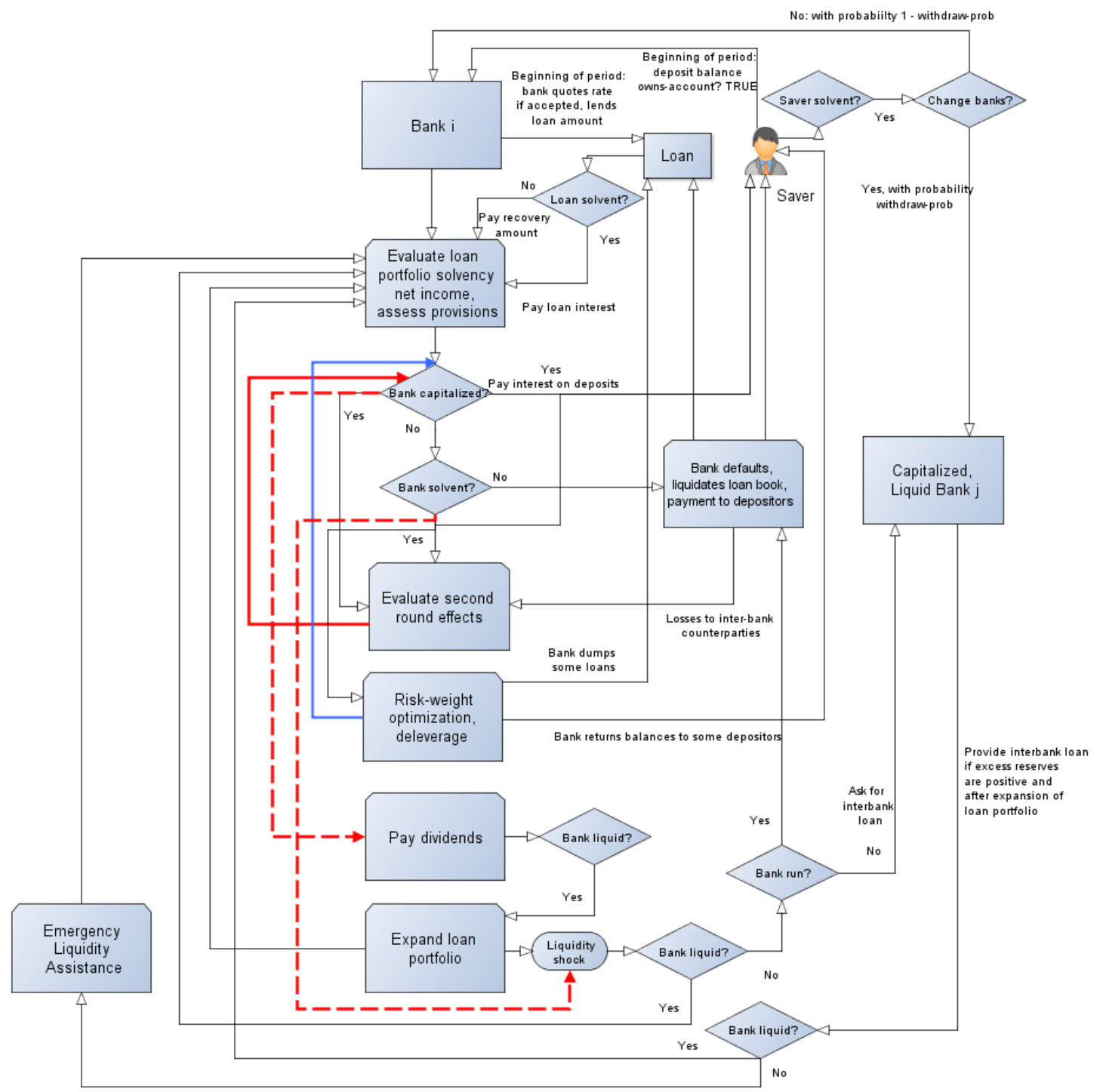

\section{BANKS’ BehaVioral Decisions AND INTERACTIONS WITH OTHER AgENTS}

Figure 3 shows the actions banks perform to generate profits under the constraints imposed by the regulatory requirements. These actions entail interactions with the other agents in the banking system. After setting up the initial portfolio, the analysis of the banking system in each period is characterized by a loop. First, evaluate the solvency of each bank following a round of defaults affecting its loan portfolio. Second, calculate losses from second-round effects affecting interbank exposures. Third, optimize the loan portfolio composition to meet capital requirements if needed. Fourth, banks need to decide whether to pay dividends or not, 
expand their loan portfolio, and access the interbank market if needed to cope with idiosyncratic liquidity shocks. We explain these actions and interactions below.

\section{A. Initial Loan Portfolio}

Initially, banks are endowed with a given equity amount, and raise deposits from savers without bank accounts. The total amount of deposits and equity is used to build a loan portfolio such that the bank's capital ratio and amount of reserves satisfy the minimum regulatory capital adequacy ratio and reserve ratio:

$$
\begin{aligned}
& E_{0}^{i} \geq\left(\sum_{\ell \in B_{0}^{i}} L_{0}^{\ell, i} \times r w_{0}^{\ell, i}\right) \times C A R, \text { and } \\
& \operatorname{Res}_{0}^{i} \geq\left(\sum_{d \in D_{0}^{i}} d_{0}^{i}\right) \times \mathrm{MRR}=D_{0}^{i} \times \mathrm{MRR} ;
\end{aligned}
$$

where, in equation (1), $E_{0}^{i}$ is the initial equity of the bank, $B_{0}^{i}$ is the loan portfolio of bank $i$, $L_{0}^{\ell, i}$ is the loan amount of loan $\ell$ held by the bank, $r w_{0}^{\ell, i}$ is the loan's corresponding risk weight, and $C A R$ is the regulatory capital adequacy ratio. In equation (2), $\operatorname{Res}_{0}^{i}$ are the reserves held by the bank, $D_{0}^{i}$ is the bank's total amount of deposits, which is equal to the sum of savers' deposits with bank $i, \sum_{d \in D_{0}^{i}} d_{0}^{i}$, and MRR is the minimum reserve ratio. All the quantities carry the subscript 0 to indicate that their values correspond to the initial period. For a subsequent period $t$ the subscript is simply changed to $t$.

Because loans can default, the bank also carries provisions against expected losses, which are calculated as:

$$
\operatorname{prov}_{0}^{i}=\sum_{\ell \in B_{0}^{i}} p_{0}^{\ell} \times L_{0}^{\ell, i} \times\left(1-r r_{0}^{\ell, i}\right),
$$

where $\operatorname{prov}_{0}^{i}$ denotes the stock of provisions (or allowance for loan losses) of bank $i, p_{0}^{\ell}$ is the default probability of loan $\ell$ in the loan portfolio, and $r r_{0}^{\ell, i}$ is the recovery rate given default.

When extending a loan, banks need to quote a lending rate that accounts for the risk of the loan. Several loan pricing models can be used. In this model, it is assumed that the bank charges a markup, $\mu_{0}^{i}$, over the fair price of the loan, yielding a lending rate, $r_{0}^{\ell, i}$, equal to:

$$
r_{0}^{\ell, i}=\mu_{0}^{i}\left[\frac{\left(1+r_{0}^{\text {free }}-p_{0}^{\ell, i} \times r r_{0}^{\ell, i}\right)}{1-p_{0}^{\ell, i}}-1\right]
$$




\section{B. Evaluating the solvency of the bank after the loan portfolio experiences defaults}

After the initial deposit raising and setup of the loan portfolio, it is necessary to calculate the net income of the bank at the beginning of every period. To calculate net income, the net interest income of the bank is reduced by the amount of credit losses and the net changes in provisions.

Net interest income, $N I I_{t}^{i}$, is calculated as:

$$
N I I_{t}^{i}=\sum_{\ell \in B_{t}^{s, i}} L_{t}^{\ell, i} \times r_{t}^{\ell, i}+\operatorname{Res}_{t-1}^{i} \times r_{t}^{R}-\sum_{d \in D_{t-1}^{i}} d_{t-1}^{i} \times r_{t}^{d, i}-E L A_{t}^{i}\left(1+r_{t}^{E L A, i}\right),
$$

where $B_{t}^{S, i}$ is the set of solvent loans of bank $i$ at time $t, r_{t}^{\ell, i}$ is the interest rate paid by loan $\ell$, $r_{t}^{R}$ is the interest earned on reserves, $r_{t}^{d, i}$ is the interest bank $i$ pays to its depositors, ELA is the liquidity assistance received by the bank, and the interest rate charged on liquidity assistance loans is $r_{t}^{E L A, i}$

Loans in default, $\ell \in B_{t}^{D, i}$, lead to credit losses, $C \operatorname{Loss}_{t}^{i}$,:

$$
\operatorname{CLoss}_{t}^{i}=\sum_{\ell \in B_{t}^{D, i}} L_{t}^{\ell, i} \times\left(1-r r_{t}^{\ell, i}\right)
$$

a change in the level of provisions, $\Delta \operatorname{prov}_{t}^{i}$ :

$$
\Delta \operatorname{prov}_{t}^{i}==\sum_{\ell \in B_{t}^{S, i}} p_{t}^{\ell} \times L_{0}^{\ell, i} \times\left(1-r r_{0}^{\ell, i}\right)-\sum_{\ell \in B_{t}^{S, i} \cup B_{t}^{D, i}} p_{t}^{\ell} \times L_{0}^{\ell, i} \times\left(1-r r_{0}^{\ell, i}\right)
$$

and to a decline in the amount of risk-weighted assets of the bank, $\mathrm{RWA}_{t}^{i}$, to

$$
\mathrm{RWA}_{t}^{i}=\sum_{\ell \in B_{t}^{S, i} \cup B_{t}^{D, i}} L_{t}^{\ell, i} \times r w_{t}^{\ell, i}-\sum_{\ell \in B_{t}^{D, i}} L_{t}^{\ell, i} \times r w_{t}^{\ell, i}
$$

After experiencing credit losses, the new equity of the bank becomes:

$$
E_{t}^{i}=E_{t-1}^{i}+N I I_{t}^{i}-\operatorname{CLoss}_{t}^{i}-\Delta \operatorname{prov}_{t}^{i}
$$

while reserves become:

$$
\operatorname{Res}_{t}^{i}=\operatorname{Res}_{t-1}^{i}+N I I_{t}^{i}+\sum_{\ell \in B_{t}^{D, i}} L_{t}^{\ell, i} \times r r_{t}^{\ell, i}-\Delta \operatorname{prov}_{t}^{i} .
$$

If $E_{t}^{i} \leq 0$, the bank is insolvent and the solvents loans in its portfolio are liquidated at firesale value generating fire-sale proceeds, $F S$, equal to: 


$$
F S_{t}^{i}=\sum_{\ell \in B_{t}^{s, i}} L_{t}^{\ell, i} \times\left(1-f s_{t}^{\ell, i}\right),
$$

where $f s_{t}^{\ell, i}$ is the fire-sale loss incurred by selling loan $\ell$. The fire-sale proceeds and reserves of the bank are used to compensate savers on a first-come, first-serve basis. In consequence, some savers may become insolvent if the fire-sale proceeds are less than the amount of deposits to be returned to savers.

\section{Second round effects}

After evaluating the solvency of each bank after the initial round of defaults, it is possible to evaluate the second round effects generated by losses in the interbank loan market. Since it is assumed that interbank loans are unsecured, credit losses in the interbank market experienced by bank $i, I B L o s s_{t}^{i}$, are calculated as:

$$
\operatorname{IBLoss}_{t}^{i}=\sum_{b \in F_{t}^{D, i}} I B_{t}^{i, b},
$$

where $F I_{t}^{D, i}$ is the set of defaulted banks with liabilities to bank $i$, and $I B_{t}^{i, b}$ are the interbank loan amount bank $i$ lent to bank $b$.

The second-round equity of the bank, $E_{t}^{I B, i}$, is obtained by deducting the interbank credit losses from the banks' equity after adding the net interest income from interbank loans that remain current:

$$
E_{t}^{I B, i}=E_{t}^{i}+\sum_{b \in F_{t}^{s, i}} I B_{t}^{i, b} \times r_{t}^{I B, i, b}-\sum_{b \in F I_{t}^{-i}} I B_{t}^{b, i} \times r_{t}^{I B, b, i}-I B \operatorname{Loss}_{t}^{i},
$$

where $r_{t}^{I B, i, b}$ and $r_{t}^{I B, b, i}$ are the interbank rates charged by and charged to bank $i, F I_{t}^{S, i}$ is the set of solvent banks with liabilities to bank $i$, and $F I_{t}^{-i}$ is the set of all banks excluding bank $i$. Note that equation (13) assumes that even insolvent creditor banks honor interbank loan interest payments. Because ABBA has a modular structure, it is possible to relax this assumption if needed.

Similarly, the second-round reserves, $\mathrm{RES}_{t}^{I B, i}$, are calculated as:

$$
\operatorname{RES}_{t}^{I B, i}=\mathrm{RES}_{t}^{i}+\sum_{b \in F I_{t}^{S, i}} I B_{t}^{i, b} \times\left(1+r_{t}^{I B, i, b}\right)-\sum_{b \in F I_{t}^{-i}} I B_{t}^{b, i} \times\left(1+r_{t}^{I B, b, i}\right)-I B L o s S_{t}^{i} .
$$

Second-round effects may cause the failure of banks which initially withstood credit losses in their loan portfolio. This would generate another round of second-round effects until the number of solvent banks remain unchanged. 


\section{Risk-Weight Optimization}

After accounting for second-round effects, a bank may remain solvent but undercapitalized, i.e. $0 \leq E_{t}^{i} \leq \mathrm{RWA}_{t}^{i} \times C A R$. In this case, the bank attempts to improve its balance sheet by performing risk-weight optimization or deleveraging. By reducing the amount of loans it holds, the bank can release provisions and boost up its equity, offsetting loan liquidation losses. At the same time, the bank reduces its amount of risk-weighted assets by the riskweighted assets of the discarded loans. Both effects help to strengthen the bank's capital ratio, and if strong enough, the bank may be again well capitalized. Note that risk-weight optimization could also raise the reserve ratio as long as the released provisions exceed the loan liquidation losses.

Mathematically, when performing risk-weight optimization the bank retains a subset of loans, $B_{t}^{R W O, S, i}$, of its solvent loan portfolio, $B_{t}^{S, i}$, that satisfies:

$$
B_{t}^{R W O, S, i} \subset B_{t}^{S, i} \text { s.t. } C A R\left(\operatorname{RWA}\left(B_{t}^{R W O, S, i}\right)\right) \geq C A R \geq C A R\left(\operatorname{RWA}\left(B_{t}^{S, i}\right)\right) .
$$

In this case, the change in the equity of the bank (and its reserves) is equal to:

$$
\Delta E_{t}^{R W O, i}=\sum_{b \in B_{t}^{S, i}, b \notin B_{t}^{R W O, S, i},}\left[p_{t}^{b} \times\left(1-r r_{t}^{b}\right)-f s_{t}^{b}\right] \times L_{t}^{b}
$$

and the change in risk-weighted assets is equal to:

$$
\Delta \mathrm{RWA}_{t}^{R W O, i}=\sum_{b \in B_{t}^{S, i}, b \notin B_{t}^{R W O, S, i}} L_{t}^{b} \times r w_{t}^{b} .
$$

It is possible to use different criteria for choosing the subset $B_{t}^{R W O, S, i}$. If optimization is used, the risk-weight optimized loan portfolio of the bank is:

$$
B_{t, o p t}^{R W O, S, i}=\underset{B}{\arg \max }\left\{B \subset B_{t}^{S, i} \text { s.t. } C A R\left(\operatorname{RWA}\left(B_{t}^{R W O, S, i}\right)\right) \geq C A R \geq C A R\left(\operatorname{RWA}\left(B_{t}^{S, i}\right)\right)\right\} .
$$

Optimization may be unfeasible if the loan portfolio is large. An alternative is to perform sequential risk-weight enhancement. In this case, loans are examined at random and disposed of as long as the associated released provisions offset the disposal costs. An advantage of sequential enhancement over optimization is that there may not be a loan portfolio such that equation (18) is satisfied. However, by enhancing the loan portfolio sequentially it is still possible to improve the capital adequacy of the portfolio even if the minimum capital adequacy ratio is not achieved.

\section{E. Dividend payment and loan book expansion}

A bank that meets capital and reserve requirements may not necessarily retain all of its net income and increase its equity. Higher equity implies a lower leverage ratio and a lower 
return on equity. Rather, a bank sets a maximum capital ratio target and after determining the amount of equity needed to meet this target, returns the excess equity to its shareholders as dividends. Since dividends are paid to shareholders from bank reserves, the maximum amount of dividends is also constrained by the excess reserves the bank holds above those needed to meet the minimum reserve requirement. More generally, the bank may specify its own internal minimum reserve target above the regulatory requirement. This target then becomes the reserve constraint faced by the bank when paying dividends.

Excess capital, $x E_{t}^{i}$, over an equity target, $E_{t}^{\text {target }}$, is calculated as:

$$
x E_{t}^{i}=E_{t}^{i}-E_{t}^{\mathrm{target}} \text {, where } E_{t}^{\mathrm{target}}=\alpha \times C A R \times \mathrm{RWA}_{t}^{i},
$$

where $\alpha>1$ determines the bank's desired capital ratio. Similarly, the amount of excess reserves, $x \mathrm{RES}_{t}^{i}$, over a reserves target, $\mathrm{RES}_{t}^{\text {target }}$ are calculated as:

$$
x \mathrm{RES}_{t}^{i}=\mathrm{RES}_{t}^{i}-\mathrm{RES}_{t}^{\mathrm{target}} \text {, where } \mathrm{RES}_{t}^{\mathrm{target}}=\beta \times M R R \times D_{t}^{i} .
$$

The dividend payment, $\operatorname{div}_{t}^{i}$, is then:

$$
\operatorname{div}_{t}^{i}=\min \left\{x E_{t}^{i}, x \operatorname{RES}_{t}^{i}\right\}
$$

Banks enjoying excess capital and excess reserves after paying dividends will expand their loan portfolio as long as regulatory requirements are met. The basic model does not allow banks to raise additional deposits to fund the expansion of their loan portfolio but it is not difficult to accommodate this in an extension of the model.

\section{F. Liquidity shocks, interbank lending and emergency liquidity assistance}

Once dividends are paid, liquidity shocks affect banks. These shocks originate from the withdrawal of deposits by a number of savers, who may decide to switch banks randomly. In the basic model, the liquidity shock does not affect system liquidity since the deposit withdrawals and reserve losses experienced by a bank are offset by the deposit inflows to other banks. ${ }^{4}$

If deposit withdrawals exceed reserves, the bank experiences a bank run and fails. In this case, the bank closes and its loan portfolio is liquidated (see equation 11 above and corresponding discussion in section III.B).

As long as they are well capitalized, banks holding positive reserves but unable to meet the minimum reserve requirements after experiencing deposit withdrawals can obtain interbank loans from well capitalized banks enjoying excess reserves (see equation 20 above). The

\footnotetext{
${ }^{4}$ Non-negligible aggregate liquidity shocks can be incorporated easily by modeling savers' entry in and exit of the banking system.
} 
amount of excess reserves available for interbank loans, however, may not be enough to meet the needs of all banks experiencing liquidity shortages. Such case, for instance, could realize if banks' reserves decline drastically owing to losses from credit shocks and second round effects.

There is liquidity rationing in the interbank market. Banks experiencing a liquidity shortage access the interbank market sequentially, in a random order. If system-wide excess reserves exceed the liquidity needs of the bank accessing the interbank market, banks with excess reserves provide interbank loans. The amount of the loans is proportional to the creditor bank share in aggregate excess reserves. For instance, if the creditor bank account for 20 percent of total excess reserves in the system, it provides 20 percent of the needs of the illiquid bank. These interbank loans create linkages, or directed edges in graph theory language, between banks and expose creditor banks to counterparty risk. ${ }^{5}$

Illiquid banks that are last in the queue may not be able to meet fully their liquidity needs in the interbank market. Their liquidity needs, together with those of undercapitalized banks, are met through emergency liquidity assistance (ELA) facilities provided by the central bank or the authorities. The basic ABBA platform presented here does not include ELA facilities as an additional agent or proto-agent now, but future extensions could incorporate it to analyze the costs and benefits of supporting illiquid banks.

\section{A Simulation EXERCise: CAPITAL AND LIQUidity REQUIREMENTS, INTERCONNECTEDNESS AND BANK FAILURES}

This section presents a concise overview of a simulation exercise aimed at analyzing the impact of capital and reserve ratio requirements on bank failures, profitability, and interconnectedness risk, with the full details of the numerical simulations presented in ChanLau (2014). We first review the basic assumptions before describing the main findings.

\section{A. Basic Assumptions and Simulation Details}

\section{Savers}

- There are 10,000 savers distributed evenly across the 10 different regions.

- Savers hold bank deposits with a unit balance.

- The bank pays a deposit rate of 1 percent.

- Interest on deposits is consumed upon receipt so the balance of the bank deposit remains constant and equal to one.

- A saver withdraws deposits and changes banks with a probability sampled from a discrete uniform distribution with values in the set $\{0,0.01, \ldots, 0.20\}$.

\footnotetext{
${ }^{5}$ In comparison to simpler static balance sheet network models, interbank loans are only used to meet liquidity needs and not to fund assets. Hence, debtor banks are not exposed to funding risk if the creditor bank fails. See Chan-Lau (2013, Chapter 8) for a discussion of these models and further references, and Bookstaber , Paddrik, and Tivnan(2014) for an ABM of the wholesale funding market.
} 


\section{Loans}

- The number of available loans is 20,000, evenly distributed across the 10 different regions. The number of loans exceeds the number of savers ensuring that there are loans available whenever banks want to expand their balance sheet.

- The loan amount is set equal to 1 .

- The recovery rate given default is assumed constant and equal to 40 percent.

- Each loan is assigned a probability of default sampled from a discrete uniform distribution with values in the set $\{0,0.1,0.2 \ldots 0.10\}$.

- The risk weight of a loan is a linear function of its probability of default, given by $0.5+5 \times$ Probability of default, with range $[0.5,1]$.

- The fire-sale loss, in percent of the face value of the loan, is sampled from a discrete uniform distribution with values in the set $\{0,0.1,0.2 \ldots 0.10\}$.

- The loan rate quoted by a bank depends on the probability of default of the loan, and set according to equation (4).

\section{Banks}

- There are 10 banks.

- The initial equity of the bank is set equal to 100 .

- Banks prefer to hold a reserve ratio equal to $1 \frac{1}{2}$ times the minimum reserves ratio requirement.

- The upper bound or maximum capital ratio preferred by the bank is $1 \frac{1 / 2}{2}$ times the CAR. Whenever the upper bound is exceeded, excess capital is distributed as dividends if there are enough deposits.

- The actions of the bank and its interaction with other agents follow the decision rules in section III.

\section{Interbank loans}

- The interbank loan rate is set equal to 1 percent.

- All banks enjoying excess reserves lend to well capitalized but illiquid banks. A lending bank lends an amount proportional to its share in total excess reserves in the banking system (see section III for details).

\section{Emergency Liquidity Assistance}

- Undercapitalized but solvent banks borrow enough deposits from the ELA facility at a zero interest rate.

- Solvent banks return funds to the ELA facility in the next period.

- There are no penalties if failed banks do not return funds; costs to ELA are not accounted explicitly.

\section{Regulatory requirements}

- Capital requirements, measure as equity to risk-weighted assets, were allowed to take values in $[0.04,0.08,0.12,0.16]$. 
- The minimum reserve ratio was allowed to take values in [0.03, 0.045, 0.06].

\section{Simulations}

- One hundred simulations, each comprising 240 periods, were performed for each of the twelve combinations of capital requirement and reserve requirement. This corresponds roughly to weekly observations over a period of 4 years.

- After banks build up their initial deposit base and loan portfolio, the simulation proceeds according to the sequence outlined in Figure 3:

- Credit losses in the loan portfolio, net income and provisions are evaluated.

- If banks become insolvent, second-round effects (i.e. credit losses from interbank loans) on other banks are evaluated. If the second-round effects prompt additional bank failures, their impact on surviving banks is reassessed.

- Well capitalized banks pay dividends.

- If banks become undercapitalized, they perform risk-weight optimization (reduce balance sheet) in order to increase their capital ratio. Insolvent banks are shut down and unwind their loan portfolios.

- Banks experience either net positive and liquidity shocks as savers shift deposits from one bank to another.

- Well capitalized but illiquid banks access the interbank market, borrowing from banks with excess reserves. Solvent but undercapitalized banks access emergency liquidity assistance. Banks facing a run fail and unwind their loan portfolios.

\section{B. Main Findings}

\section{Bank Failures: the Interplay of Solvency and Liquidity Requirements}

At low capitalization levels, banks are more vulnerable to credit shocks are more likely to be undercapitalized. Banks unable to meet the regulatory capital requirement would have their access to the interbank market curtailed, raising the liquidity risk of the bank. This is the case presented in the top left panel in Figure 4.

When the capital requirement is 4 percent, it is difficult for banks to keep their reserve ratio at the target level set at 50 percent above the minimum reserve ratio. Furthermore, after a number of periods, banks on average are not able to meet the minimum reserve ratio and have to rely on the ELA facilities. This does not constitute a problem once capital requirements are 8 percent or above. In these cases, banks on average can meet their target reserve ratios. 
Figure 4. Average reserve ratio for different regulatory requirements, in percent
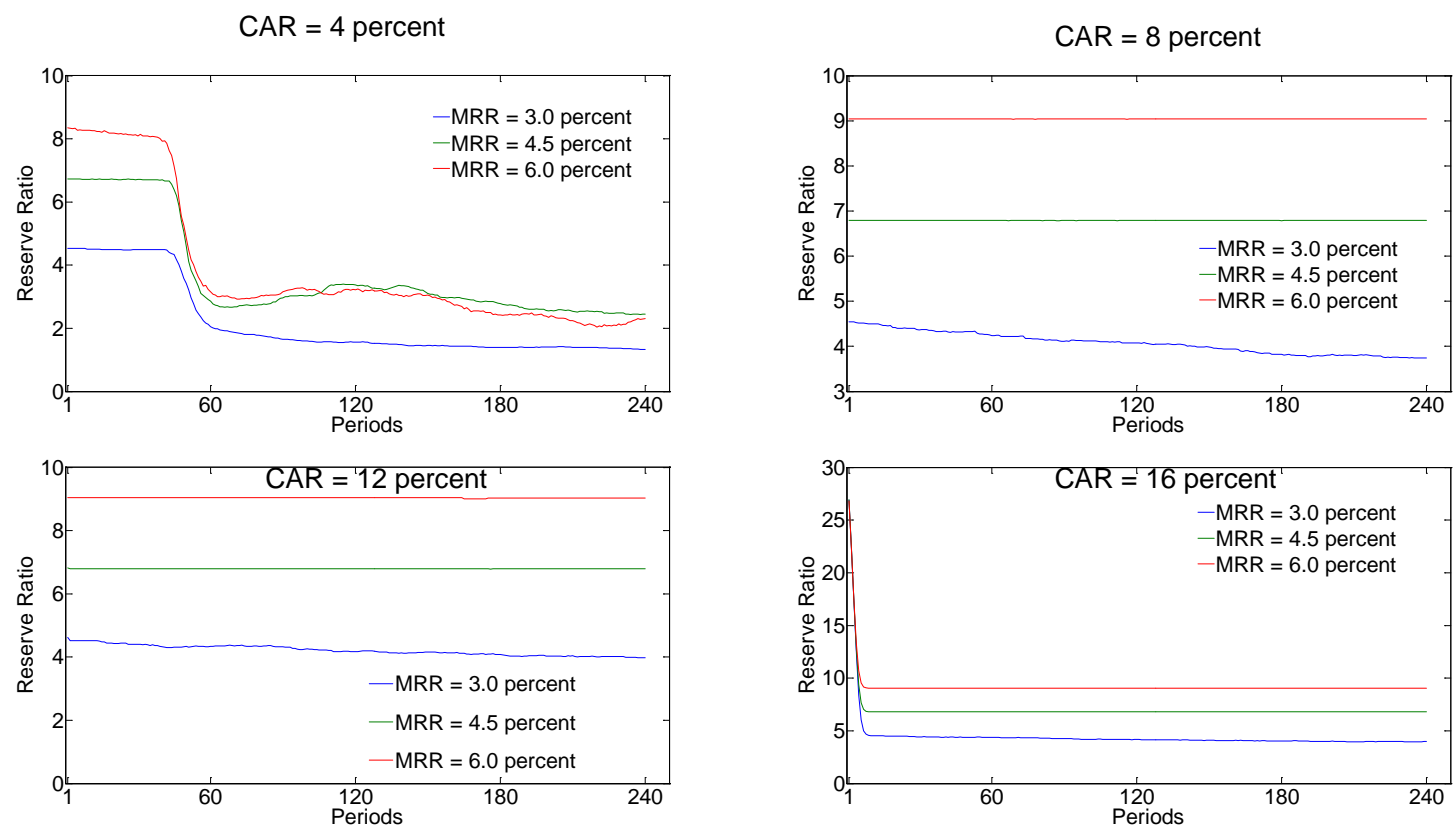

Source: Author's calculations.

In addition, there is an interesting interplay between capital requirements and reserve requirements when the former are set at low levels, which is 4 percent in this analysis. Higher reserve requirements force banks to hold more reserves, reducing the impact of liquidity shocks and their associated failures (Table 1). When banks are undercapitalized, however, higher reserve requirements prevent banks from performing risk-weight optimization, which requires running down the reserves of the bank. Therefore, higher reserve requirements lead to an increase in the number of credit failures, offsetting the lower number of liquidity failures.

The amount of reserves held by the bank also constrains its ability to distribute dividends. As indicated in section III.A, the simulations assume banks target capital ratio 50 percent higher than the minimum requirement, i.e. with a CAR of 8 percent, a bank will start distributing dividends if its capital ratio exceeds 12 percent. 
Table 1. Credit and liquidity failures for different regulatory requirement, in percent

Percentages calculated as the average percent of bank failures across all simulated periods in the 100 simulations performed for each combination of regulatory requirements.

\begin{tabular}{|c|c|c|c|}
\hline \multirow[t]{2}{*}{ Type of failure } & \multicolumn{3}{|c|}{ Minimum reserve ratio } \\
\hline & 3 percent & 4.5 percent & 6 percent \\
\hline \multicolumn{4}{|c|}{ Panel A: Minimum capital adequacy ratio $=4$ percent } \\
\hline $\begin{array}{l}\text { Failures, in percent } \\
\text { of which (in perce }\end{array}$ & 43.8 & 38.2 & 46.8 \\
\hline Liquidity & 27.5 & 14.7 & 16.0 \\
\hline Credit & 16.3 & 23.5 & 30.8 \\
\hline \multicolumn{4}{|c|}{ Panel B: Minimum capital adequacy ratio $=8$ percent } \\
\hline $\begin{array}{l}\text { Failures, in percent } \\
\text { of which (in perce }\end{array}$ & 8.6 & 0.0 & 0.0 \\
\hline Liquidity & 8.6 & 0.0 & 0.0 \\
\hline Credit & 0.0 & 0.0 & 0.0 \\
\hline \multicolumn{4}{|c|}{ Panel C: Minimum capital adequacy ratio $=12$ percent } \\
\hline $\begin{array}{l}\text { Failures, in percent } \\
\text { of which (in perce }\end{array}$ & 6.0 & 0.0 & 0.0 \\
\hline Liquidity & 6.0 & 0.0 & 0.0 \\
\hline Credit & 0.0 & 0.0 & 0.0 \\
\hline \multicolumn{4}{|c|}{ Panel D: Minimum capital adequacy ratio $=16$ percent } \\
\hline $\begin{array}{l}\text { Failures, in percent } \\
\text { of which (in perce }\end{array}$ & 6.4 & 0.0 & 0.0 \\
\hline Liquidity & 6.4 & 0.0 & 0.0 \\
\hline Credit & 0.0 & 0.0 & 0.0 \\
\hline
\end{tabular}

Source: Author's calculations.

When the capital requirement is set to 8 percent or more, banks on average are able to keep their capital ratio at roughly their maximum target regardless of the reserve ratio requirement. In contrast, when the capital requirement is low, at 4 percent, banks set a low capital ratio target, which may be more difficult to achieve after experiencing credit and liquidity shocks. In this case, the banks are more reluctant to pay dividends since they need to rebuild their capital base. Moreover, paying dividends becomes more difficult as reserve ratios increase (Figure 5). 
Figure 5. Mean capital ratio for different regulatory requirements, in percent

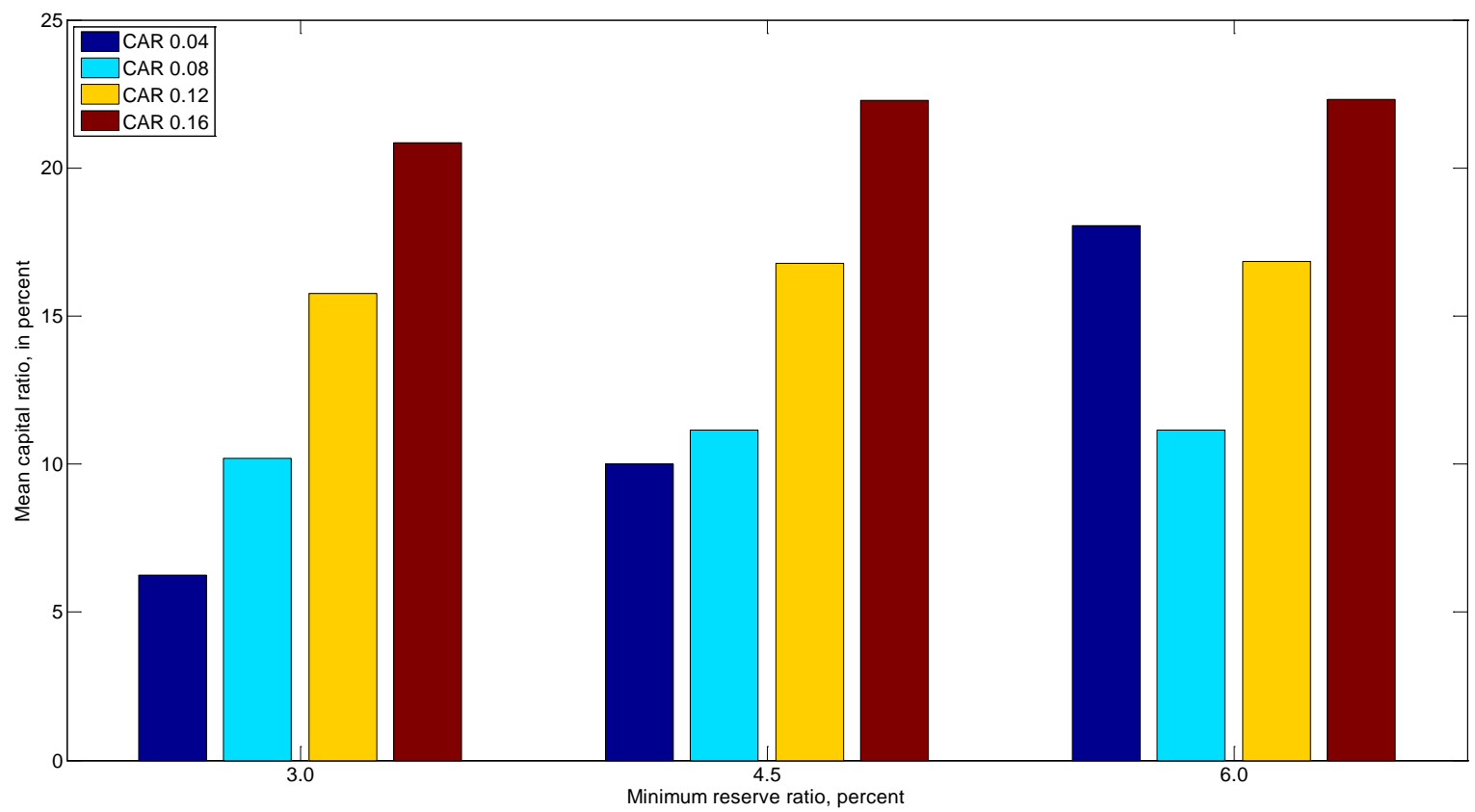

Source: Author's calculations.

\section{Profitability}

When banks are required to hold capital ratios of 8 percent or above, bank profitability, measured as return on equity, appears driven mainly by regulatory capital requirements and only slightly affected by the reserve requirement ratio (Figure 8). For high capital ratios, return on equity is higher the lower capital requirements are as expected. Higher reserve requirements encourage banks to hold higher reserve levels - remember banks target a buffer above the regulatory requirement-which enhances their capacity to distribute dividends and raise the return on equity.

The only exception occurs when capital requirements are low. As explained above, when banks target a low capital ratio it becomes more difficult to pay dividends, which hurts the return on equity. Figure 6, hence mirrors the results in Figure 5. 
Figure 6. Mean return on equity under different regulatory requirements, in percent

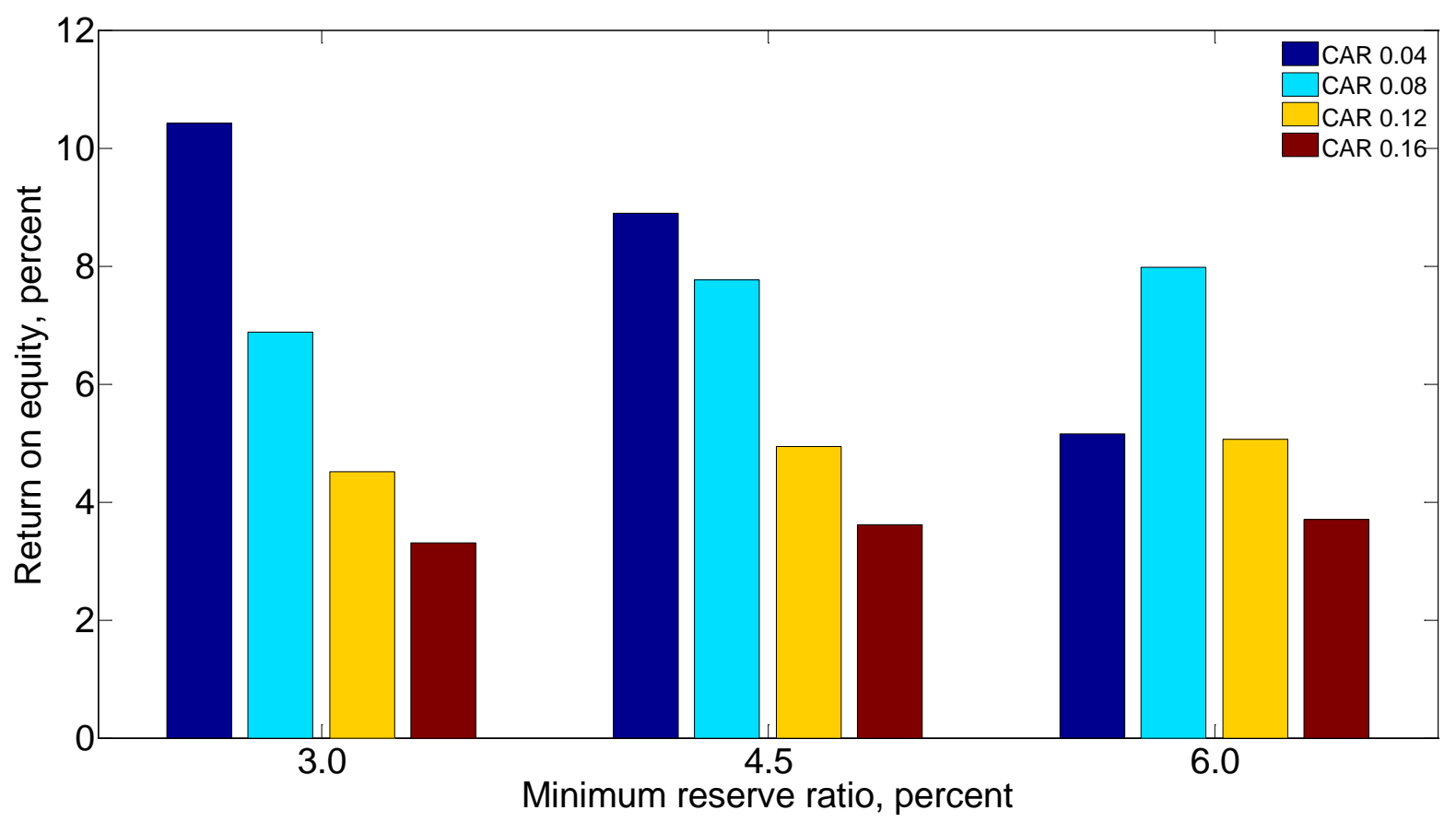

Source: Author's calculations.

\section{Interconnectedness}

In this banking system, interconnectedness arises endogenously as banks facing liquidity pressures prompted by deposit withdrawals borrow reserves in the interbank market. In the NetLogo implementation of ABBA, red lines show the interbank loans going from banks with excess reserves to banks facing liquidity problems (Figure 7). In this particular example, each borrowing bank receives an interbank loan from four banks, which yields an in-degree of four. Correspondingly, the lending banks have an out-degree of two, corresponding to the two interbank loans they extend. 
Figure 7. NetLogo implementation of ABBA showing interbank loans

Banks in yellow are borrowers, bank in green are well capitalized banks, and interbank loans are shown as red lines. Only banks enjoying excess reserves lend in the interbank market. Banks in brown have already failed owing to a bank run (see section III).

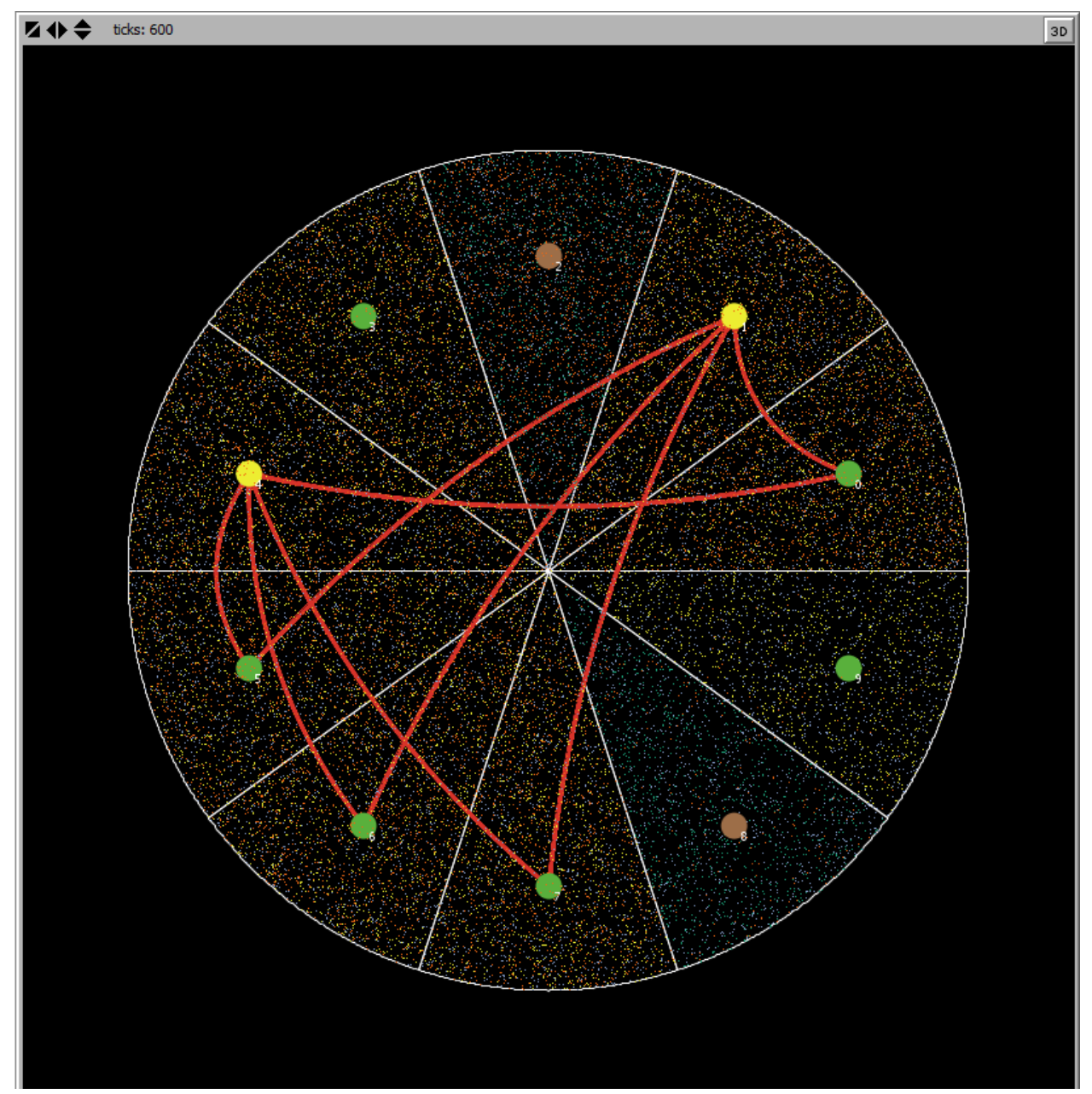

Over time, the number of in-degrees of a bank changes randomly (Figure 8). Borrowing banks may switch and become lending banks, and vice-versa. In several dates, there can be as many as seven creditor banks, which is a high degree of interconnectedness in a system with only ten banks. These results just discussed, however, should not detract from the fact that on average, most of the time most banks are not highly connected to each other, as reported in Tables 2 and 3, and summarized in Figure 9. 
Figure 8. In-degree and Out-degree dynamics for a representative bank

Based on one representative simulation comprising 240 periods and different regulatory requirement combinations.

Minimum reserve ratio

3 percent
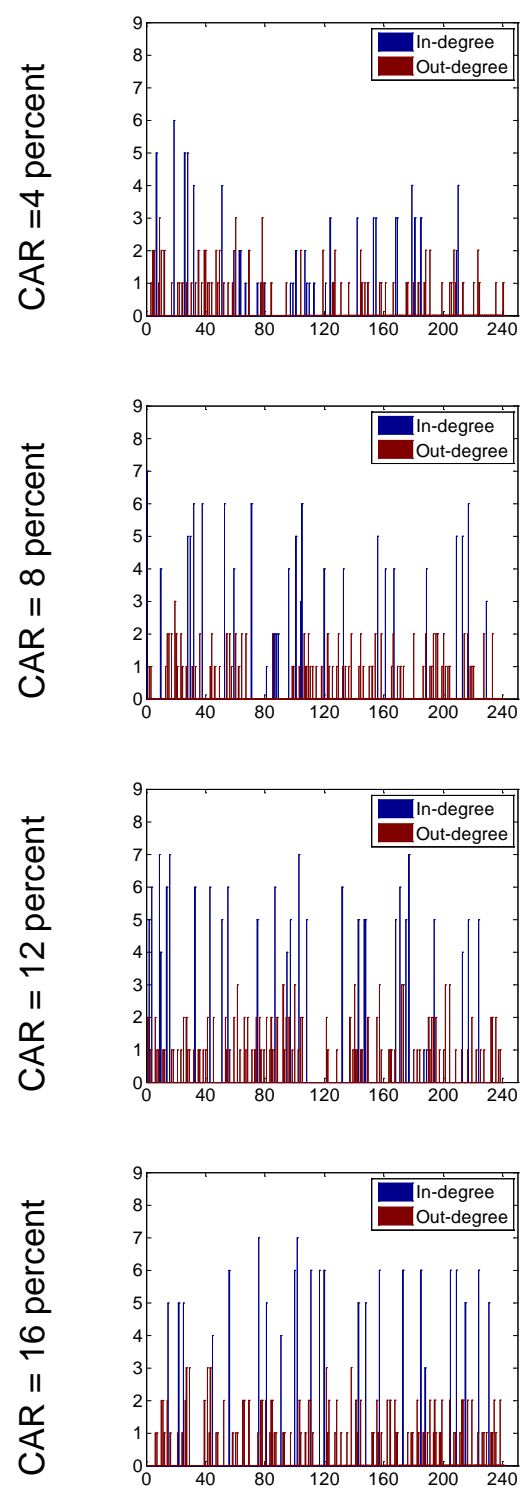

4.5 percent
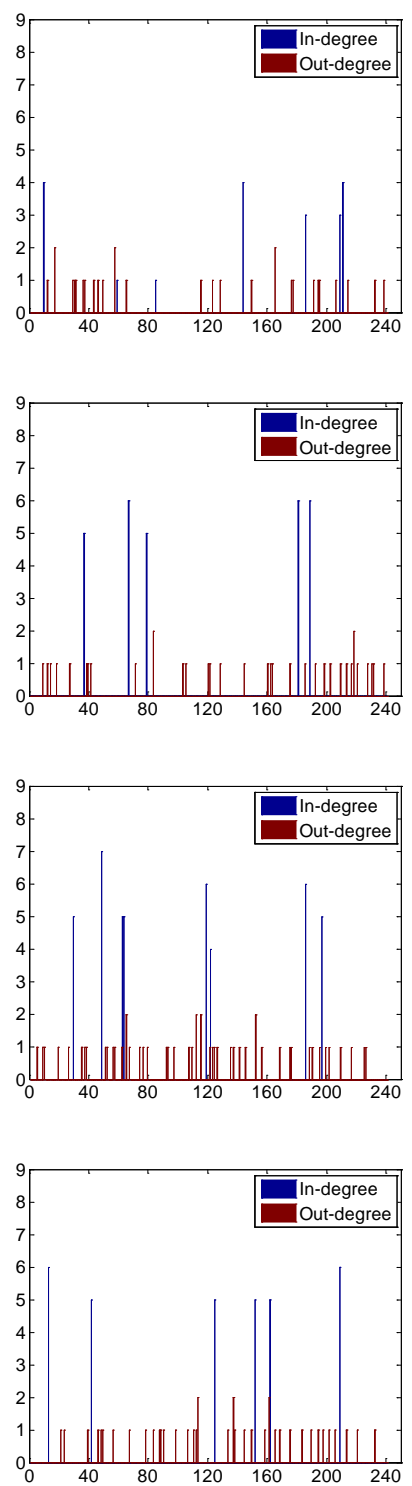

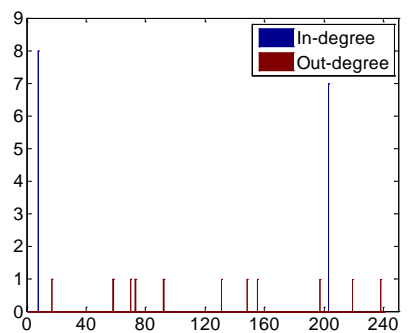

6 percent
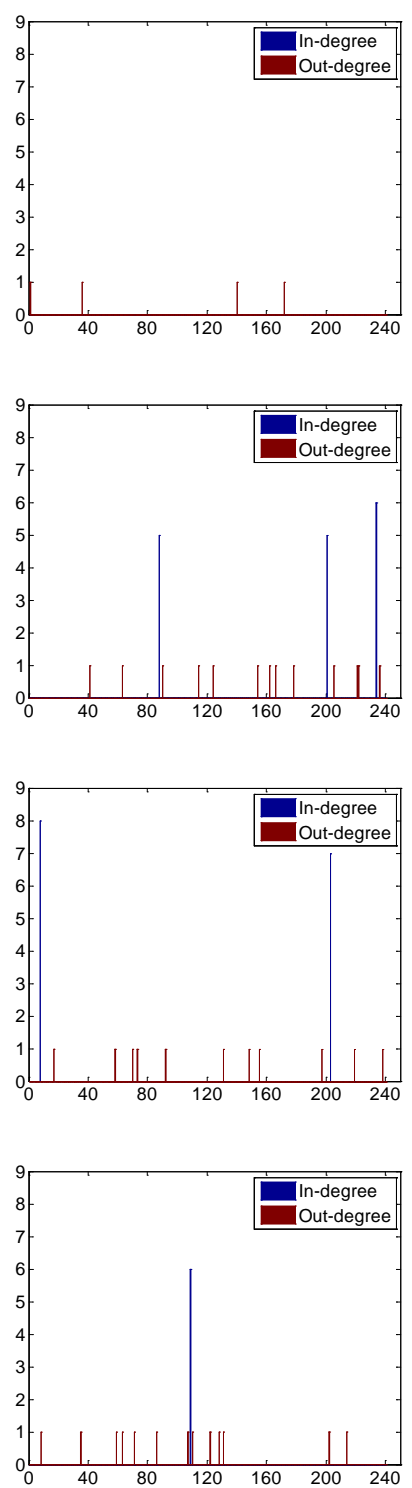

Source: Author's calculations.

Regardless of the different combinations of regulatory requirements, on average, the indegree of a bank, or the bank's number of creditor banks, is zero ninety percent of the time, suggesting either no need for interbank borrowings, or the failure of the bank to qualify as a 
creditworthy borrower (Table 2). Similarly, on average, the out-degree of a bank is zero about seventy percent of the time, indicating banks seldom supply funds in the interbank market. When banks are net creditors, they lend on average to one bank twenty percent of the time, and to two banks the remaining ten percent of the time (Table 3 and Figure 9).

Figure 9. Percent of times out-degree of a bank exceeds one

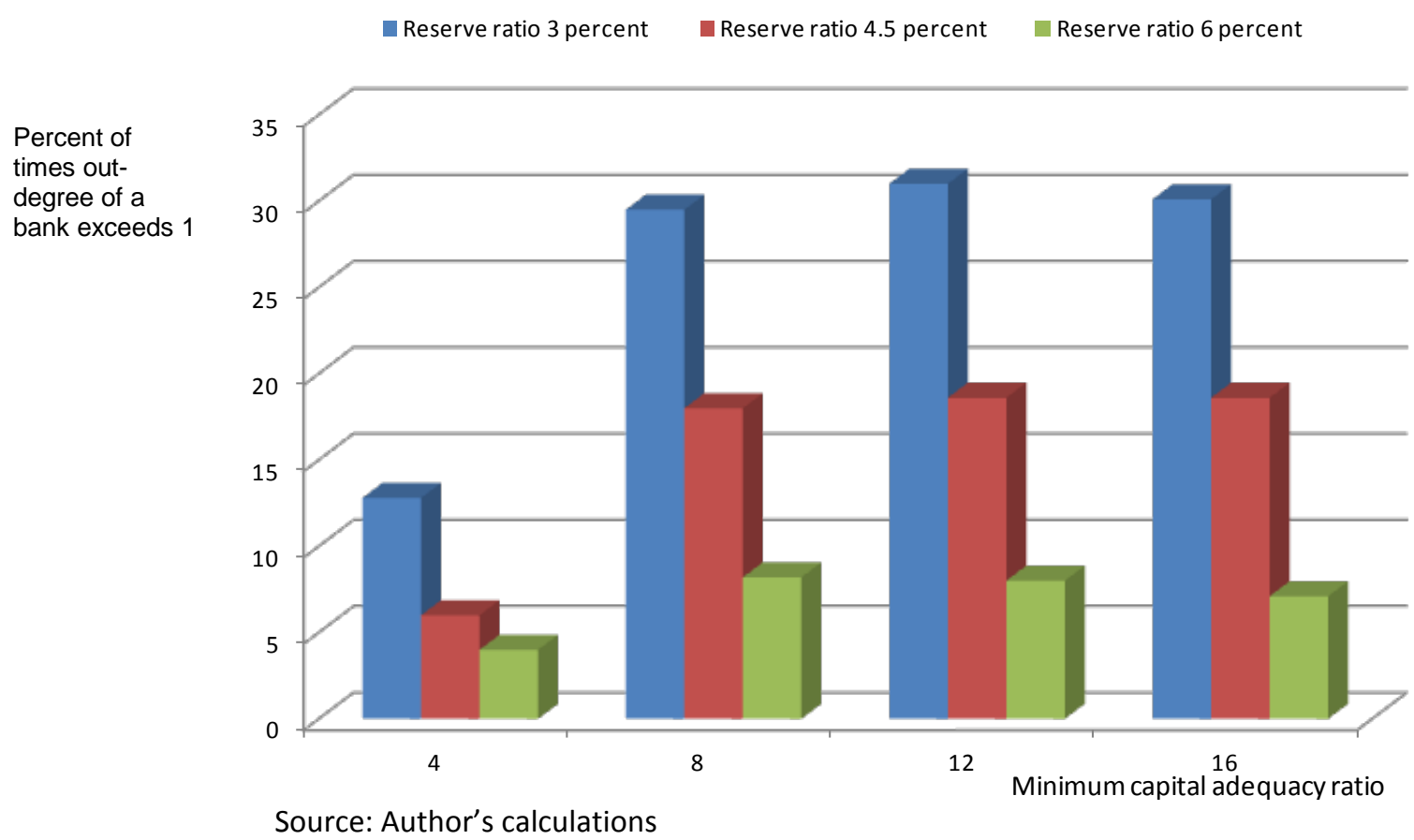

From a long run perspective, interconnectedness is typically low, though in some periods the system can become highly connected, with a few banks connected to a large number of creditor banks. Table 2 presents the maximum number of connections under the columns reporting the maximum in-degree value. In-degree values of six and higher realize with certain frequency at about seven to nine percent of the time, especially when reserve requirements do not exceed $4 \frac{1}{2}$ percent Table 3 reveals that interconnectedness arise mainly from the fact that many banks lend to a single bank rather than several banks borrowing from a single bank. The maximum number of out-degrees for a single bank seldom exceeds three during the simulations.

Paradoxically, an increase in capital requirement could increase interconnectedness when initial capital levels are low (Tables 2 and 3, mean columns, Panels A and B, and Figure 9). With higher capital ratio targets, it is less likely that banks are undercapitalized, which facilitates access to the interbank market when facing liquidity shortages. Finally, holding the capital requirement constant, higher reserve requirements induce higher reserve targets, reducing the need for interbank borrowings and interconnectedness in the banking system (Figure 9). 


\section{Table 2. Banks' in-degree for different regulatory requirements, in percent}

For each simulation, each comprising 240 periods, the table reports the percent of occurrences when the indegree value assumes a given value. The minimum, mean, and maximum are calculated over 100 simulations.

\begin{tabular}{|c|c|c|c|c|c|c|c|c|c|}
\hline \multirow{2}{*}{$\begin{array}{c}\text { In- } \\
\text { degree }\end{array}$} & \multicolumn{3}{|c|}{ Minimum reserve ratio: 3 percent } & \multicolumn{3}{|c|}{ Minimum reserve ratio: 4.5 percent } & \multicolumn{3}{|c|}{ Minimum reserve ratio: 6 percent } \\
\hline & Min & Mean & $\operatorname{Max}$ & Min & Mean & $\operatorname{Max}$ & Min & Mean & $\operatorname{Max}$ \\
\hline & \multicolumn{9}{|c|}{ Panel A: Minimum capital adequacy ratio: 4 percent } \\
\hline 0 & 83.3 & 94.3 & 100.0 & 86.7 & 97.7 & 100.0 & 91.3 & 98.8 & 100.0 \\
\hline 1 & 0.0 & 2.3 & 12.9 & 0.0 & 1.0 & 11.3 & 0.0 & 0.2 & 5.0 \\
\hline 2 & 0.0 & 0.5 & 4.2 & 0.0 & 0.1 & 2.5 & 0.0 & 0.0 & 1.3 \\
\hline 3 & 0.0 & 0.4 & 5.0 & 0.0 & 0.2 & 3.3 & 0.0 & 0.1 & 1.3 \\
\hline 4 & 0.0 & 0.6 & 6.7 & 0.0 & 0.3 & 4.2 & 0.0 & 0.2 & 2.1 \\
\hline 5 & 0.0 & 1.0 & 6.7 & 0.0 & 0.3 & 3.8 & 0.0 & 0.3 & 4.6 \\
\hline 6 & 0.0 & 0.7 & 5.0 & 0.0 & 0.3 & 2.1 & 0.0 & 0.3 & 4.6 \\
\hline 7 & 0.0 & 0.2 & 2.5 & 0.0 & 0.1 & 0.8 & 0.0 & 0.1 & 1.3 \\
\hline 8 & 0.0 & 0.0 & 0.4 & 0.0 & 0.0 & 0.4 & 0.0 & 0.0 & 0.4 \\
\hline \multirow[t]{2}{*}{9} & 0.0 & 0.0 & 0.0 & 0.0 & 0.0 & 0.0 & 0.0 & 0.0 & 0.0 \\
\hline & \multicolumn{9}{|c|}{ Panel B: Minimum capital adequacy ratio: 8 percent } \\
\hline 0 & 84.2 & 91.3 & 100.0 & 87.5 & 96.0 & 99.6 & 90.0 & 98.2 & 100.0 \\
\hline 1 & 0.0 & 0.5 & 8.3 & 0.0 & 0.1 & 7.9 & 0.0 & 0.0 & 2.1 \\
\hline 2 & 0.0 & 0.2 & 3.8 & 0.0 & 0.0 & 2.1 & 0.0 & 0.0 & 1.7 \\
\hline 3 & 0.0 & 0.4 & 7.9 & 0.0 & 0.1 & 5.4 & 0.0 & 0.0 & 0.8 \\
\hline 4 & 0.0 & 1.5 & 5.8 & 0.0 & 0.5 & 5.8 & 0.0 & 0.2 & 2.9 \\
\hline 5 & 0.0 & 3.1 & 9.2 & 0.0 & 1.4 & 5.8 & 0.0 & 0.6 & 5.0 \\
\hline 6 & 0.0 & 2.5 & 7.1 & 0.0 & 1.4 & 5.4 & 0.0 & 0.7 & 5.4 \\
\hline 7 & 0.0 & 0.6 & 2.9 & 0.0 & 0.4 & 2.1 & 0.0 & 0.2 & 1.7 \\
\hline 8 & 0.0 & 0.0 & 0.8 & 0.0 & 0.0 & 0.8 & 0.0 & 0.0 & 0.8 \\
\hline \multirow[t]{2}{*}{9} & 0.0 & 0.0 & 0.0 & 0.0 & 0.0 & 0.4 & 0.0 & 0.0 & 0.0 \\
\hline & \multicolumn{9}{|c|}{ Panel C: Minimum capital adequacy ratio: 12 percent } \\
\hline 0 & 83.8 & 91.1 & 100.0 & 88.3 & 95.9 & 99.6 & 91.3 & 98.3 & 100.0 \\
\hline 1 & 0.0 & 0.3 & 7.9 & 0.0 & 0.0 & 4.2 & 0.0 & 0.0 & 2.1 \\
\hline 2 & 0.0 & 0.2 & 4.2 & 0.0 & 0.0 & 1.7 & 0.0 & 0.0 & 1.3 \\
\hline 3 & 0.0 & 0.4 & 5.0 & 0.0 & 0.1 & 2.9 & 0.0 & 0.0 & 2.1 \\
\hline 4 & 0.0 & 1.7 & 7.5 & 0.0 & 0.6 & 4.6 & 0.0 & 0.2 & 3.3 \\
\hline 5 & 0.0 & 3.3 & 7.9 & 0.0 & 1.6 & 5.8 & 0.0 & 0.6 & 4.6 \\
\hline 6 & 0.0 & 2.5 & 7.1 & 0.0 & 1.4 & 4.6 & 0.0 & 0.6 & 3.8 \\
\hline 7 & 0.0 & 0.6 & 3.3 & 0.0 & 0.4 & 2.9 & 0.0 & 0.2 & 1.7 \\
\hline 8 & 0.0 & 0.0 & 0.8 & 0.0 & 0.0 & 0.8 & 0.0 & 0.0 & 0.8 \\
\hline \multirow[t]{2}{*}{9} & 0.0 & 0.0 & 0.0 & 0.0 & 0.0 & 0.0 & 0.0 & 0.0 & 0.4 \\
\hline & \multicolumn{9}{|c|}{ Panel D: Minimum capital adequacy ratio: 16 percent } \\
\hline 0 & 84.2 & 91.5 & 100.0 & 87.9 & 95.8 & 100.0 & 90.4 & 98.3 & 100.0 \\
\hline 1 & 0.0 & 0.3 & 8.3 & 0.0 & 0.1 & 4.2 & 0.0 & 0.2 & 7.1 \\
\hline 2 & 0.0 & 0.2 & 4.2 & 0.0 & 0.0 & 1.3 & 0.0 & 0.1 & 2.5 \\
\hline 3 & 0.0 & 0.3 & 4.2 & 0.0 & 0.1 & 2.5 & 0.0 & 0.0 & 0.8 \\
\hline 4 & 0.0 & 1.6 & 5.8 & 0.0 & 0.5 & 2.9 & 0.0 & 0.2 & 2.5 \\
\hline 5 & 0.0 & 3.1 & 8.3 & 0.0 & 1.5 & 6.7 & 0.0 & 0.5 & 3.8 \\
\hline 6 & 0.0 & 2.4 & 7.1 & 0.0 & 1.4 & 6.3 & 0.0 & 0.5 & 2.5 \\
\hline 7 & 0.0 & 0.6 & 3.3 & 0.0 & 0.4 & 2.1 & 0.0 & 0.2 & 1.7 \\
\hline 8 & 0.0 & 0.1 & 1.3 & 0.0 & 0.0 & 0.8 & 0.0 & 0.0 & 0.4 \\
\hline 9 & 0.0 & 0.0 & 0.4 & 0.0 & 0.0 & 0.4 & 0.0 & 0.0 & 0.0 \\
\hline
\end{tabular}

Source: Author's calculations. 


\section{Table 3. Banks' out-degree for different regulatory requirements, in percent}

For each simulation, each comprising 240 periods, the table reports the percent of occurrences when the indegree value assumes a given value. The minimum, mean, and maximum are calculated over 100 simulations.

\begin{tabular}{|c|c|c|c|c|c|c|c|c|c|}
\hline \multirow{2}{*}{$\begin{array}{c}\text { Out- } \\
\text { degree }\end{array}$} & \multicolumn{3}{|c|}{ Minimum reserve ratio: 3 percent } & \multicolumn{3}{|c|}{ Minimum reserve ratio: 4.5 percent } & \multicolumn{3}{|c|}{ Minimum reserve ratio: 6 percent } \\
\hline & Min & Mean & $\operatorname{Max}$ & Min & Mean & Max & Min & Mean & $\operatorname{Max}$ \\
\hline & \multicolumn{9}{|c|}{ Panel A: Minimum capital adequacy ratio: 4 percent } \\
\hline 0 & 56.7 & 87.2 & 99.6 & 78.3 & 94.0 & 100.0 & 73.8 & 96.0 & 100.0 \\
\hline 1 & 0.4 & 8.6 & 29.2 & 0.0 & 5.4 & 17.1 & 0.0 & 2.9 & 15.8 \\
\hline 2 & 0.0 & 3.5 & 17.1 & 0.0 & 0.6 & 5.4 & 0.0 & 1.0 & 10.4 \\
\hline 3 & 0.0 & 0.6 & 4.6 & 0.0 & 0.0 & 1.3 & 0.0 & 0.2 & 2.5 \\
\hline 4 & 0.0 & 0.0 & 0.8 & 0.0 & 0.0 & 0.8 & 0.0 & 0.0 & 0.8 \\
\hline 5 & 0.0 & 0.0 & 0.4 & 0.0 & 0.0 & 0.0 & 0.0 & 0.0 & 0.0 \\
\hline 6 & 0.0 & 0.0 & 0.0 & 0.0 & 0.0 & 0.0 & 0.0 & 0.0 & 0.0 \\
\hline 7 & 0.0 & 0.0 & 0.0 & 0.0 & 0.0 & 0.0 & 0.0 & 0.0 & 0.0 \\
\hline 8 & 0.0 & 0.0 & 0.0 & 0.0 & 0.0 & 0.0 & 0.0 & 0.0 & 0.0 \\
\hline \multirow[t]{2}{*}{9} & 0.0 & 0.0 & 0.0 & 0.0 & 0.0 & 0.0 & 0.0 & 0.0 & 0.0 \\
\hline & \multicolumn{9}{|c|}{ Panel B: Minimum capital adequacy ratio: 8 percent } \\
\hline 0 & 52.9 & 70.5 & 100.0 & 64.6 & 82.0 & 95.4 & 70.8 & 91.8 & 99.2 \\
\hline 1 & 0.0 & 18.2 & 28.8 & 3.8 & 15.2 & 27.1 & 0.8 & 6.8 & 20.4 \\
\hline 2 & 0.0 & 9.5 & 20.0 & 0.0 & 2.5 & 13.8 & 0.0 & 1.2 & 12.9 \\
\hline 3 & 0.0 & 1.7 & 5.8 & 0.0 & 0.3 & 3.3 & 0.0 & 0.2 & 3.3 \\
\hline 4 & 0.0 & 0.1 & 0.8 & 0.0 & 0.0 & 0.4 & 0.0 & 0.0 & 0.8 \\
\hline 5 & 0.0 & 0.0 & 0.4 & 0.0 & 0.0 & 0.4 & 0.0 & 0.0 & 0.4 \\
\hline 6 & 0.0 & 0.0 & 0.0 & 0.0 & 0.0 & 0.0 & 0.0 & 0.0 & 0.0 \\
\hline 7 & 0.0 & 0.0 & 0.4 & 0.0 & 0.0 & 0.0 & 0.0 & 0.0 & 0.0 \\
\hline 8 & 0.0 & 0.0 & 0.0 & 0.0 & 0.0 & 0.0 & 0.0 & 0.0 & 0.0 \\
\hline \multirow[t]{2}{*}{9} & 0.0 & 0.0 & 0.0 & 0.0 & 0.0 & 0.0 & 0.0 & 0.0 & 0.0 \\
\hline & \multicolumn{9}{|c|}{ Panel C: Minimum capital adequacy ratio: 12 percent } \\
\hline 0 & 53.3 & 69.0 & 100.0 & 63.3 & 81.4 & 96.3 & 71.7 & 92.0 & 98.3 \\
\hline 1 & 0.0 & 19.4 & 30.8 & 3.8 & 15.6 & 27.9 & 1.3 & 6.7 & 20.0 \\
\hline 2 & 0.0 & 9.9 & 19.2 & 0.0 & 2.7 & 12.9 & 0.0 & 1.1 & 10.8 \\
\hline 3 & 0.0 & 1.6 & 5.4 & 0.0 & 0.3 & 3.8 & 0.0 & 0.2 & 2.9 \\
\hline 4 & 0.0 & 0.1 & 0.8 & 0.0 & 0.0 & 0.4 & 0.0 & 0.0 & 0.4 \\
\hline 5 & 0.0 & 0.0 & 0.4 & 0.0 & 0.0 & 0.0 & 0.0 & 0.0 & 0.0 \\
\hline 6 & 0.0 & 0.0 & 0.0 & 0.0 & 0.0 & 0.0 & 0.0 & 0.0 & 0.0 \\
\hline 7 & 0.0 & 0.0 & 0.0 & 0.0 & 0.0 & 0.0 & 0.0 & 0.0 & 0.0 \\
\hline 8 & 0.0 & 0.0 & 0.0 & 0.0 & 0.0 & 0.0 & 0.0 & 0.0 & 0.0 \\
\hline \multirow[t]{2}{*}{9} & 0.0 & 0.0 & 0.0 & 0.0 & 0.0 & 0.0 & 0.0 & 0.0 & 0.0 \\
\hline & \multicolumn{9}{|c|}{ Panel D: Minimum capital adequacy ratio: 16 percent } \\
\hline 0 & 54.2 & 69.9 & 97.5 & 63.3 & 81.4 & 92.5 & 82.1 & 92.9 & 98.8 \\
\hline 1 & 1.3 & 19.2 & 32.1 & 6.3 & 15.4 & 26.7 & 1.3 & 6.1 & 14.2 \\
\hline 2 & 0.0 & 9.3 & 17.9 & 0.0 & 2.9 & 14.2 & 0.0 & 0.9 & 6.7 \\
\hline 3 & 0.0 & 1.6 & 5.4 & 0.0 & 0.3 & 3.8 & 0.0 & 0.1 & 1.7 \\
\hline 4 & 0.0 & 0.1 & 0.8 & 0.0 & 0.0 & 0.8 & 0.0 & 0.0 & 0.4 \\
\hline 5 & 0.0 & 0.0 & 0.4 & 0.0 & 0.0 & 0.0 & 0.0 & 0.0 & 0.0 \\
\hline 6 & 0.0 & 0.0 & 0.0 & 0.0 & 0.0 & 0.0 & 0.0 & 0.0 & 0.0 \\
\hline 7 & 0.0 & 0.0 & 0.0 & 0.0 & 0.0 & 0.0 & 0.0 & 0.0 & 0.0 \\
\hline 8 & 0.0 & 0.0 & 0.0 & 0.0 & 0.0 & 0.0 & 0.0 & 0.0 & 0.0 \\
\hline 9 & 0.0 & 0.0 & 0.0 & 0.0 & 0.0 & 0.0 & 0.0 & 0.0 & 0.0 \\
\hline
\end{tabular}

Source: Author's calculations. 


\section{CONCLUSIONS}

This paper has introduced a simple modular agent-based model, ABBA, for analyzing risks and interactions in the banking system. Reliance on an agent-based formulation rather than on the highly aggregated models typically used in central banks and regulatory agencies, makes possible to account for heterogeneity and adaptive behavior in the banking system. Hence, the model can accommodate features such as endogenous bank networks arising through interbank loans, and dynamic bank balance sheet adjustment through risk-weight optimization, dividend payments, and loan book expansion.

By modeling market participants as agents, and enriching the set of actions available to them, ABBA can support policy guidance on financial regulation and evaluate risks associated with what-if scenarios. In an illustrative example, numerical simulations uncover linkages between different regulatory requirements and solvency, liquidity and interconnectedness risk in the banking system. This assessment would not have been possible using aggregate models or purely econometric and statistical techniques.

In its current formulation, the ABBA platform can capture the dynamics of a traditional banking system, i.e. banks raise deposits, and interbank loans serve to meet liquidity shortages. Extending the platform to model risks in more advanced banking systems is straightforward, as it only requires including different types of agents and specifying a richer set of actions for the agents, which is relatively simple in ABM languages like NetLogo. For instance, ABBA could incorporate wholesale investors as a different type of agent, and their funding decision could be contingent on bank parameters such as the capitalization and liquidity ratios. This extension could better fit the dynamics of banking systems like those in the United Kingdom and the United States.

In this version of ABBA, unsecured loans created linkages between banks. Introducing collateralized loans may require including a different proto-agent, the collateral asset, and modeling its price dynamics. With these extensions ABBA could complement and extend models such as the one in Bookstaber, Paddrik, and Tivnan (2014). Finally, depositors were modeled as proto-agents in this model, but more complex dynamics can be incorporated to account for savers' emotional states, which are driven by the group dynamics of neighbors or other members of their social networks, as modeled for instance in Zandbergen (2013). These and other extensions can be explored in future work. 


\section{References}

Allen, F., and A. Babus, 2009, “Networks in Finance,” in P. Kleindorfer, Y. Wind, and R. Gunther, editors, The Network Challenge: Strategy, Profit, and Risk in an Interlinked World (Wharton School Publishing).

Anselmo, P. and M. Planck, 2012, "Solvency Dynamics of an Evolving Agent-Based Banking System Model,” Working Paper, New Mexico Institute of Mining and Technology.

Atkinson, T., D. Luttrell, and H. Rosenblum, 2013, "How Bad was It? The Costs and Consequences of the 2007-9 Financial Crisis,” Staff Papers No. 20, Federal Reserve Bank of Dallas.

Axtell, R., D. Farmer, J. Geanakoplos, P. Howitt, E. Carella, B. Conlee, J. Goldstein, M. Hendrey, P. Kalikman, D. Masad, N. Palmer, and C. Yang, 2014, “An Agent-Based Model of the Housing Market Bubble in Metropolitan Washington D.C.” mimeo., (George Mason University, Oxford University, Yale University and Brown University).

Aymanns, C., and J.D. Farmer, 2015, “The Dynamics of the Leverage Cycle,” Journal of Economic Dynamics and Control 50, Special Issue: Crisis and Complexity, CRISIS Workship 2013, pp. 155-179.

Babel, B., D. Gus, A. Grawert, E. Luders, A. Natale, B. Nilsson, and S. Schneider, 2012, “Capital Management: Banking's New Imperative,” McKinsey Working Papers on Risk, Number 38 (McKinsey \& Company).

Bookstaber, R., 2012, “Using Agent-Based Models for Analyzing Threats to Financial Stability,” Office of Financial Research, Working Paper No, 0003 (U.S. Department of the Treasury).

Bookstaber, R., and M. Paddrik, 2015, “An Agent-Based Model for Crisis Liquidity Dynamic,” Office of Financial Research, WP 15-18, U.S. Department of the Treasury (Washington, D.C.)

Bookstaber, R., M. Paddrik, and B. Tivnan, 2014, “An Agent-Based Model for Financial Vulnerability,” Office of Financial Research, WP 14-05, U.S. Department of the Treasury (Washington, D.C.)

Chan-Lau, J.A., 2013, Systemic Risk Assessment and Oversight (London: Risk Books).

Chan-Lau, J.A., 2014, "Regulatory Requirements and their Implications for Bank Solvency, Liquidity, and Interconnectedness Risks: Insights from Agent-Based Model Simulations,” mimeo, available at SSRN.com. 
Complexity Research Initiative for Systemic Instabilities (C.R.I.S.I.S.) http://www.crisiseconomics.edu

Cont, R., A. Mousa, and E.B. Santos, 2013, “Network Structure and Systemic Risk in Banking Systems,” in J.P. Fouque and J. Langsam, editors, Handbook of Systemic Risk (Cambridge University Press).

Diamond, D. and P. Dybvig, 1983, “Bank Runs, Deposit Insurance, and Liquidity,” Journal of Political Economy 91 (3), pp. 401-419.

Easley, D., and J. Kleinberg, 2010, Networks, Crowds, and Markets: Reasoning About a Highly Connected World (Cambridge University Press).

Fouque, J.-P., and J.A. Langsam, 2013, Handbook of Systemic Risk (Cambridge University Press).

Gaffard, J.-L., and M. Napoletano, editors, Agent-Based Models and Economic Policy, Revue de l'OFCE (Paris).

Gai, P., and S. Kapadia, 2010, “Contagion in Financial Networks,” Working Paper No. 383 (London: Bank of England).

Gai, P., A. Haldane, and S. Kapadia, 2011, “Complexity, Concentration and Contagion,” Journal of Monetary Economics 58 (5), pp. 453-70.

Gai, P., 2013, Systemic Risk: the Dynamics of Modern Financial Systems (Oxford University Press).

Georg, C.-P., 2013, “The Effect of Interbank Network Structure on Contagion and Common Shocks,” Journal of Banking and Finance 37 (7).

Gode, D., and S. Sunder, 1993, “Allocative Efficiency of Markets with Zero-Intelligence Traders: Market as a Partial Substitute for Individual Rationality,” Journal of Political Economy 101 (1), pp. 119-137.

Grilli, R., G. Tedeschi, and M. Gallegati, 2014, "Markets Connectivity and Financial Contagion,” Journal of Economic Interaction and Coordination, pp. 1 - 18, available online at Springer Link.

Haldane, A., 2009, "Rethinking the Financial Network," speech delivered at the Financial Student Association, Amsterdam, April.

International Monetary Fund, 2012, “Macrofinancial Stress Testing - Principles and Practices,” mimeo (Washington, D.C.). 
Ismail, O., 2012, “An Agent-Based Computational Model for Bank Formation and Interbank Networks,” Ph.D. dissertation, School of Computational Engineering and Science, McMasters University.

Jackson, M., 2010, Social and Economic Networks (Princeton University Press).

Klinger, T., and P. Teply, 2014, "Systemic Risk in the Global Banking System - an AgentBased Network Model Approach,” Prague Economic Papers 1, pp. 24-41.

Lenzu, S., and G. Tedeschi, 2012, “Systemic Risk on Different Interbank Network Topologies,” Quaderno di Ricerca No. 375, Universita Pollitechnica delle Marche.

Macroeconomic Assessment Group, 2010, “Assessing the Macroeconomic Impact of the Transition to Stronger Capital and Liquidity Requirements,” (Basel: Bank for International Settlements).

Montagna, M., and C. Kok, 2013, “Multi-layered Interbank Model for Assessing Systemic Risk”, Kiel Working Papers No. 1873, Kiel Institute for the World Economy.

North, M., and C.M. Macal, 2005, Managing Business Complexity: Discovering Strategic Solutions with Agent-Based Modeling and Simulation (Oxford: Oxford University Press).

Roger, S., and J. Vlcek, 2012, “Macrofinancial Modeling at Central Banks: Recent Development and Future Directions,” IMF WP /12/21 (Washington, D.C.: International Monetary Fund).

Romero, P., 2009, “Banking Crises and Institutional Arrangements,” Department of Economics, George Mason University.

Scheule, H., and D. Roesch, 2008, Stress Testing for Financial Institutions (London: Risk Books).

Siddique, A., and I. Hassan, editors, 2013, Stress Testing: Approaches, Methods and Applications (London: Risk Books).

Upper, C., 2011, "Simulation Methods to Assess the Danger of Contagion in Interbank Markets,” Journal of Financial Stability 7 (3), pp. 111-125.

Wilensky, U., 1999, NetLogo, Center for Connected Learning and Computer-Based Modeling, Northwestern University.

Zandbergen, W., 2013, “Essays on the Panic of 1893,” Ph.D. dissertation, Department of Computational Social Sciences, George Mason University.

Zhang, J., editor, 2014, CCAR and Beyond: Capital Assessment, Stress Testing and Applications (London: Risk Books). 